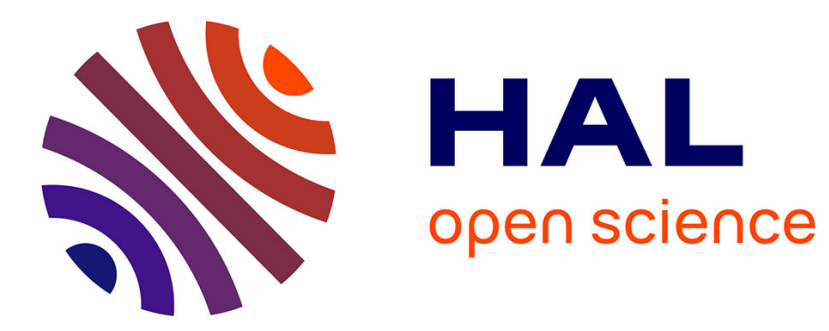

\title{
From Folds to Structures, a Review
}

Arthur Lebée

\section{To cite this version:}

Arthur Lebée. From Folds to Structures, a Review. International Journal of Space Structures, 2015, 30 (2), pp.55-74. 10.1260/0266-3511.30.2.55 . hal-01266686

\section{HAL Id: hal-01266686 \\ https://hal-enpc.archives-ouvertes.fr/hal-01266686}

Submitted on 3 Feb 2016

HAL is a multi-disciplinary open access archive for the deposit and dissemination of scientific research documents, whether they are published or not. The documents may come from teaching and research institutions in France or abroad, or from public or private research centers.
L'archive ouverte pluridisciplinaire HAL, est destinée au dépôt et à la diffusion de documents scientifiques de niveau recherche, publiés ou non, émanant des établissements d'enseignement et de recherche français ou étrangers, des laboratoires publics ou privés. 


\title{
From Folds to Structures, a Review
}

\author{
Arthur Lebée*
}

\begin{abstract}
Université Paris-Est, Laboratoire Navier (ENPC, IFSTTAR, CNRS). École des Ponts ParisTech, 6 et 8 avenue Blaise
Pascal. 77455 Marne-la-Vallée cedex2
\end{abstract}

(Submitted on 23/05/2015, Reception of revised paper 28/06/2015, Accepted on 02/07/2015)

\begin{abstract}
Starting from simple notions of paper folding, a review of current challenges regarding folds and structures is presented. A special focus is dedicated to folded tessellations which are raising interest from the scientific community. Finally, the different mechanical modeling of folded structures are investigated. This reveals efficient applications of folding concepts in the design of structures.
\end{abstract}

Key Words: Origami, Folded Tessellations, Structures, Folds

\section{INTRODUCTION}

The concept of fold covers many significations. In nature, it is mostly related to specific shapes such as creases or pleats and may be found at many different scales from the folding of graphen layers [1,2], to the unfolding of tree leaves [3] and the mountains building (orogeny). Pleated fabrics found on Egyptian frescoes prove that, long ago, mankind also handcrafted folds. However, the abstract idea of a folded surface emerged rather recently.

The triggering ingredient was the invention of paper in Asia. Notwithstanding its crucial role in the diffusion of knowledge, it allowed the achievement of the first folded models. Folding paper had a sacred meaning in ancient Japan and was called origami, concatenating "oru" (fold) and "kami" (paper) [4]. Because paper was extremely expensive at that time, origami models were first confined to religious or outstanding events such as weddings. It is only during the twentieth century that origami spread across the whole Japanese society and eventually worldwide.

Many flat materials may be folded such as fabrics or parchment. However, paper is certainly the first material which was thin enough and yet inextensible in its plane so that it was suitable for origami. Considering the geometrical transformation endured by the sheet of paper, it appears clearly that any line drawn on the sheet will keep its length constant during the transformation. This remarkable property combined with the empirical observation that many different shapes may be obtained from paper folding, suggests immediately that there are underlying rules and encourages the mathematical formalization of this process. The connection between origami and mathematics is deep and a dedicated new theoretical field of research emerged in the last decades: origami mathematics. For instance, noticing that crease lines are geometric constructions Jacques Justin defined a set of axioms which defines all geometric constructions accessible by folding. It turns out that there are more possibilities than with the classical Euclid axioms: trisecting an angle is not possible with rule and compass but it is possible with folding. There are many other questions investigated in origami mathematics such as flat foldability and continuous rigid foldability and most active researchers gather every four years at the international meeting of Origami Science, Math and Education (OSME [5]).

Anyone that has folded paper noticed the extremely rich motion which may come out from a simple organization of folds [6]. It is thus not surprising that a wide variety of technological applications are currently investigated. These many innovations combining mathematical, kinematic or structural

\footnotetext{
*Corresponding author e-mail: A Lebée arthur.lebee@enpc.fr
} 
properties of folds are referred to Origamics [7]. There are many advantages to start from a flat sheet of material. For instance, since there are neither cuts and nor offcuts, this forming process might be rather inexpensive. Similarly, the kinematic properties of folds make them extremely good candidates for designing small robots [8] or MEMS (Micro ElectroMechanical System). Many of these applications are not published in scientific journals and are often simply scattered on the Internet through blogs or shared videos. Because, origami concepts are extremely visual, this new way of sharing knowledge generated a strong enthusiasm in the last decade.

Many professions are now investigating the fascinating properties of folds. However, architects and designers were probably the firsts to identify the key role of folding as a form-finding process. At the end of the 19th century, the emergence of new construction materials and techniques such as concrete and steel put deeply into question the academic architectural style prevailing at that time. It became obvious that building and designing objects should be also driven by the fabrication process and not only by formal questions. Following this movement - from which originated Modernism - Joseph Albers introduced folds in his preliminary course of the department of design at the Bauhaus in the 20's (Figure 1 and Figure 2).

Because folding is certainly the most simple and inexpensive process for transforming matter, it is an excellent starting point for teaching architecture and design. This process enables fast and easy achievement of three dimensional shapes which clearly show better structural properties than the original sheet and defines directly an envelope, separating the "inside" from the "outside". Gathering so many interesting properties from such a simple

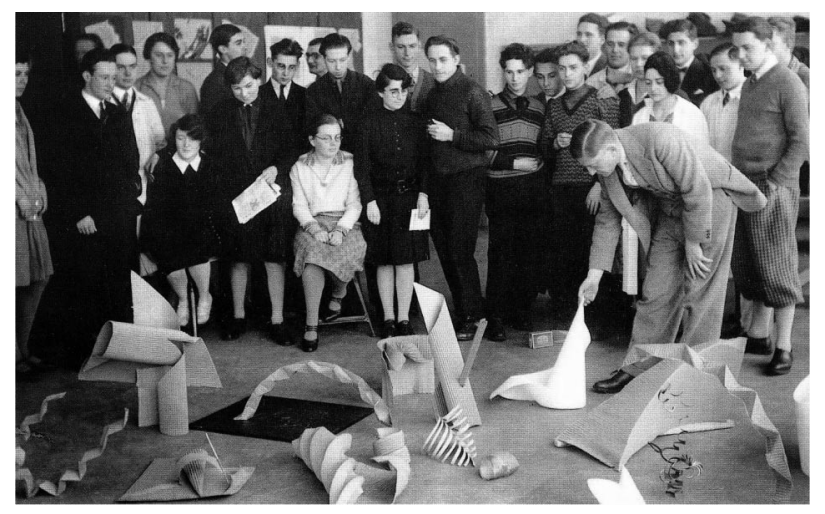

Figure 1. Josef Albers and his students at Bauhaus 1928 (photo: Bauhaus Archives).

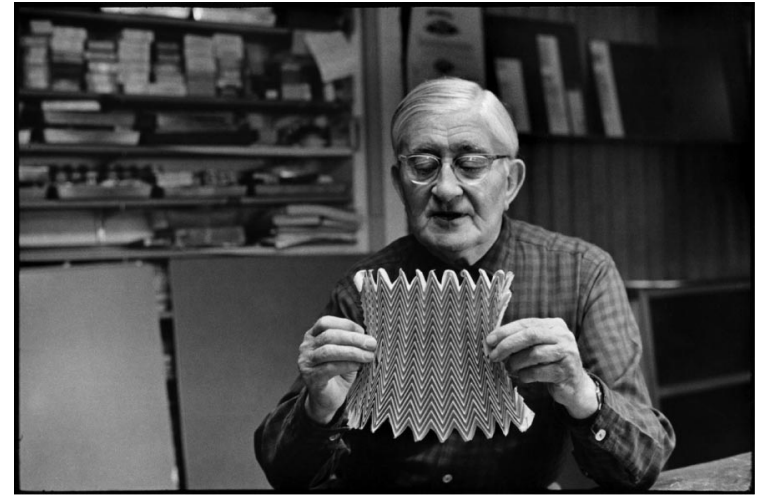

Figure 2. Josef Albers playing with Miura Ori photographed by Henri Cartier Bresson, (Magnum Photos, 1968).

transformation inspired many architects, designers and engineers such as Jean Prouvé or Pier Luigi Nervi. It is an almost impossible task to give a fair account of all the applications of origami in design and architecture. The kinematic properties of folds make them extremely versatile for designing packages and furniture with industrial materials such as cardboard or polypropylene. The moment of inertia given to a surface with pleats originally inspired many architects for designing wide roofings and recent developments were reviewed $[9,10,11]$.

Today, the combination of parametric graphical tools, new fabrication process based on numerical control and 3D printers makes architects and designer even closer to actual constructions. First, it is much faster to test the feasibility of a design thanks to rapid prototyping. The design cycle is thus strongly accelerated. Second, provided the digital format is compatible with the full scale fabrication process, architects and designer are actually directly editing working-drawings from the beginning. This strongly encourages them to have direct interactions with manufacturers. Hence it is worth to consider these evolutions as a new construction paradigm providing a new geometrical freedom which remains yet close to the manufacturing process.

In this extremely encouraging context for innovations in construction, it is worth to attempt a review focused on two key aspects: the form-finding process related to folding and the behavior as a structure of a folded shape. Starting from developable surfaces, section 2 provides an overview of interesting shapes which may be derived from folding techniques. A particular focus is provided on folded tessellations. Because a fold is the transformation of a surface, it is actually a mechanism. Hence the question of the link between folded surfaces and actual structures is not so simple and investigated in 
section 3. Even if new graphical tools offer much more freedom for finding shapes, it is worth to recall that in the end a construction will carry a load. Hence, finding a relevant mechanical modeling for a folded surface will help the understanding of its structural behavior.

\section{FOLDING AS A FORM-FINDING PROCESS}

Since no cuts are allowed, folding paper preserves the length of any curve drawn on its surface. This is actually a very particular transformation of a surface with a certain degree of regularity. Ignoring the thickness of the paper, mathematicians call this purely geometric transformation an isometric embedding.

Gauss was one of the first mathematicians to try the mathematical characterization of this kind of transformations by means of differential geometry. These investigations led him to Theorema Egregium which is probably one of his most famous results: During an isometric embeddings, the Gauss curvature is preserved. In any point of a surface with a twice differentiable $\left(C^{2}\right)$ parametrization there are two principal curvature radii and the Gauss curvature is the inverse of the product of these radii.
Since origamists start from a flat sheet of paper, the original Gauss curvature is zero. Whereas Theorema Egregium sets a purely local constraint on the Gauss curvature, in case the latter is zero everywhere on the surface this constraint may be integrated. Finally, the only $C^{2}$ surfaces which may be obtained keeping constant lengths on the surface are developable surfaces. Regular developable surfaces are limited to three kinds: cones, cylinders and tangent developable surfaces (Figure 3). Of course, keeping this high regularity restricts strongly accessible shapes and it is a common observation that one cannot wrap smoothly a sphere with a sheet of paper.

A first relaxation of regularity is to allow finite jumps of the curvature and keep a $C^{1}$ parametrization (Figure 4). In architecture, approaching a general surface with $C^{1}$ developable surfaces reduces significantly the cost of engineering and fabrication and was investigated by Pottmann et al. [13]. Another fascinating illustration of such surfaces is the solution of Nash problem [14]: transforming a flat square into a torus with the highest possible regularity without stretching or cutting (Figure 5). Interestingly, in order to satisfy the isometric transformation, the solution presents a fractal hierarchy of corrugations which is
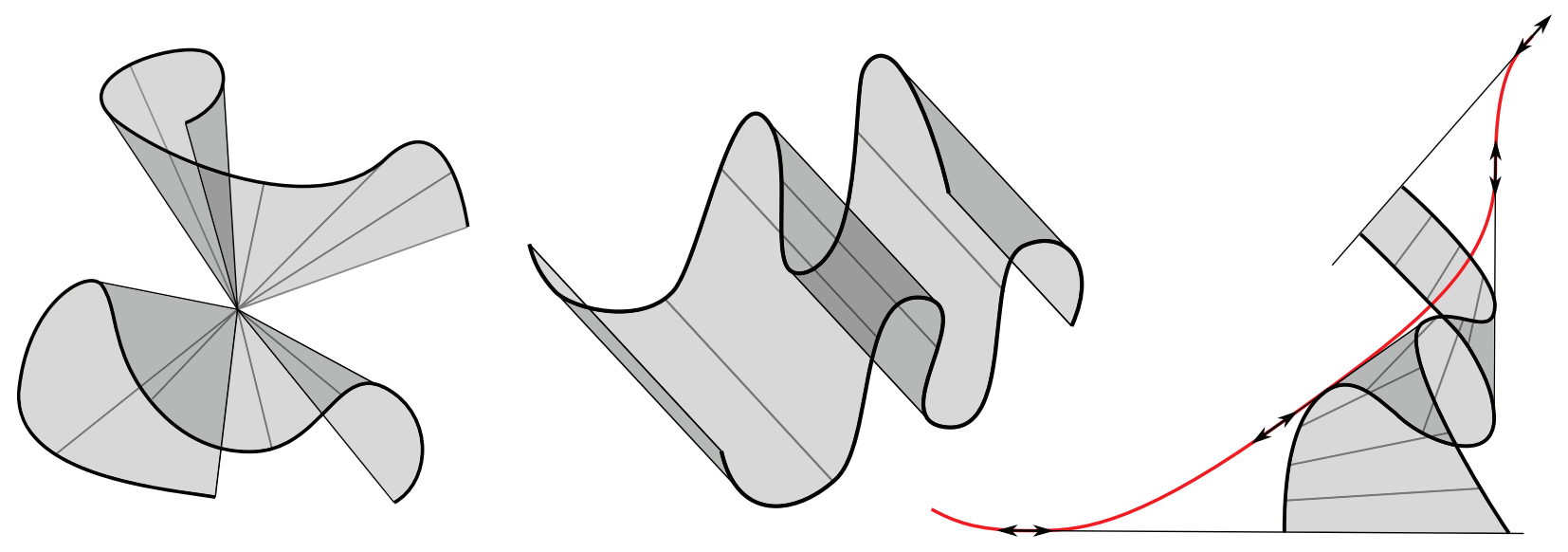

Figure 3. The three kinds of developable surfaces: cone, cylinder, tangent developable; inspired by [12].

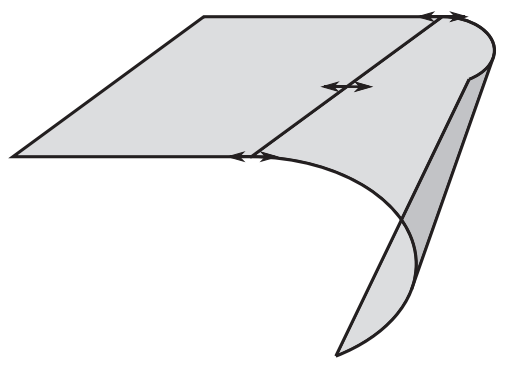

Figure 4. Matching two developable surfaces preserving $C^{1}$ continuity.

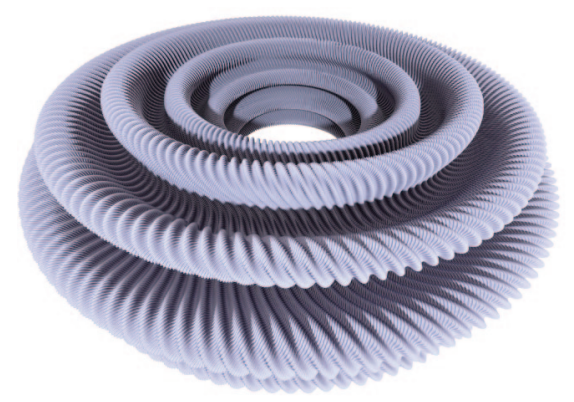

Figure 5. Isometric embedding of a square into a torus [14]. 


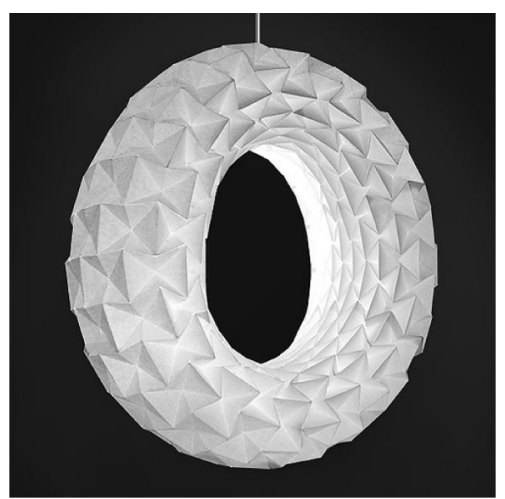

Figure 6. A torus shaped lamp based on waterbomb tesselation from Jiangmei Wu [15].

the prelude to pleats, commonly used in origami models.

If only $C^{0}$ continuity of the surface is required, linear singularities (folds) and point singularities (vertices) are allowed. Crumpled paper as well as origami fall into this definition. One may ask which shapes are accessible with these rules. There is no need of a proof to see that the answer is any and origamists achievements are clear illustrations. With folds, there are many possible answers to Nash problem (see for instance Figure 6) and pure free forms were achieved through crumpling (see the work of Jackson [16] for instance). The price for this diversity is the more complex description of this transformation.

\subsection{Folds and their simulation}

In order to explore accessible forms for a given arrangement of folds it is necessary to be able to simulate the folding kinematics. Most developments are focused currently on rigid folding and are first addressed. However, there are more general folds gathered here as curved folds - which are more challenging and discussed subsequently.

\subsubsection{Rigid folding}

Rigid folding is when all the deformation is focused in the hinges and the faces between the folds remain flat. Having a continuously rigid foldable surface is convenient because each facet is considered as a rigid solid connected to other facets only by hinges. This
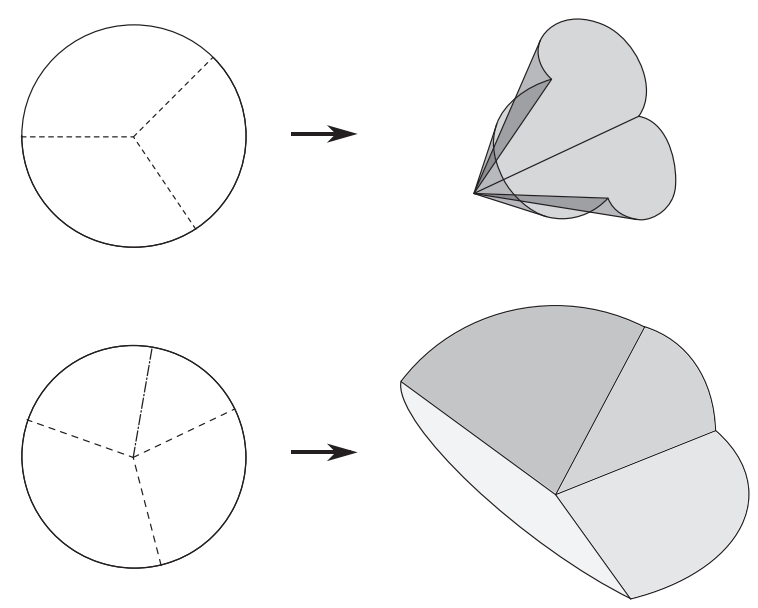

Figure 8 . Three-fold vertex and folding with bending of the faces (top) and four-fold vertex and rigid folding of the faces.

way, the number of kinematic degrees of freedom remains finite. The relevant modeling framework is of course rigid body dynamics. However, due to the possibly large number of solids, the computational burden might be too large and some simplifications coming from folding rules might be exploited.

Simple folds and vertices. When folding a sheet of paper along a straight line, one side of the sheet is freely rotating with respect to the other side along the fold line. From a flat configuration, there are two possible directions of rotation and it is common to specify these directions as mountain or valley folds (Figure 7). During the transformation, each side remains flat.

Origami models are a collection of folds which intersect at vertices. Depending on the number of fold lines which are incident on the vertex (Figure 8) a motion may or may not be possible without bending the faces around the vertices. If there are less than four incident fold lines, it is not possible to fold around the vertex without bending one or more faces [17]. With four incident lines and if all faces angles are smaller than $\pi$ there is one rigid degree of freedom [18, 19]. Adding fold lines will possibly increase the number of degrees of freedom.

These illustrating local rules are some of the necessary conditions for rigid foldablility.
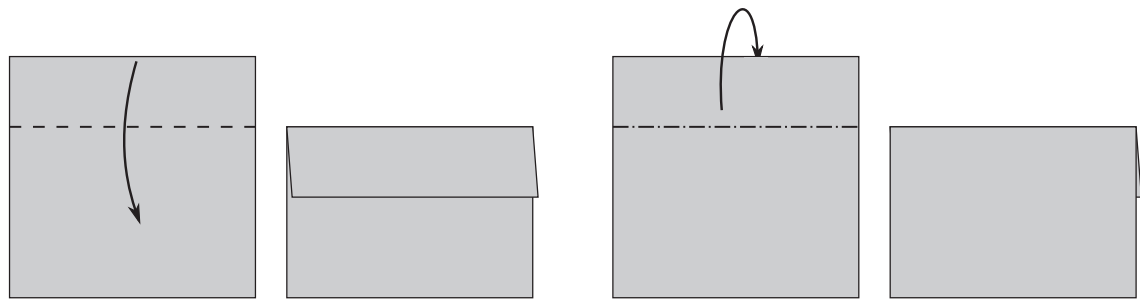

Figure 7. Valley (left) and mountain (right) fold. 

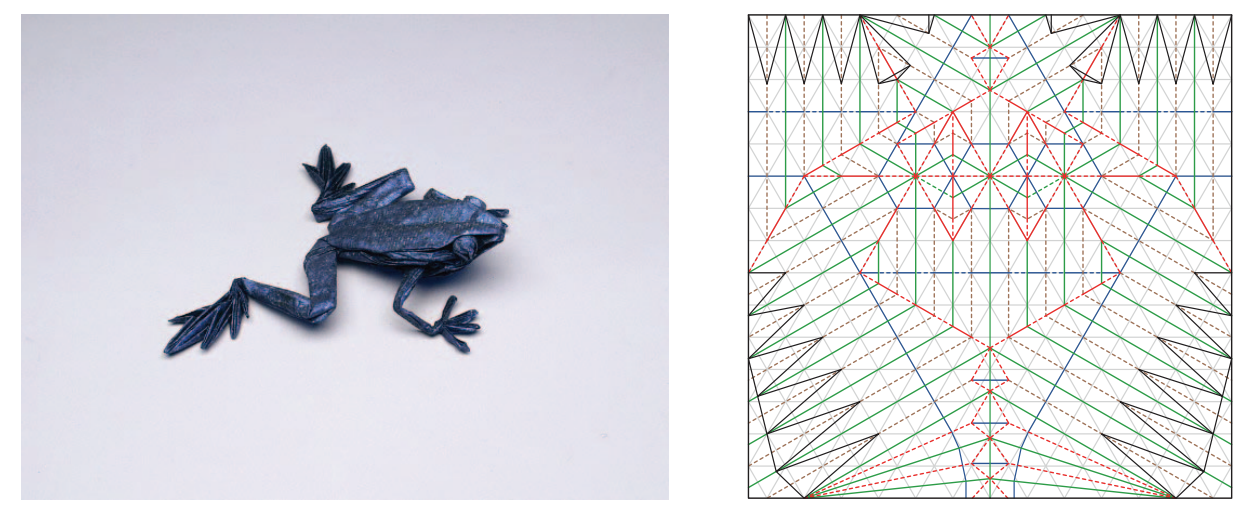

Figure 9. "Poison Dart Frog HP, opus 598" from Lang and the corresponding crease pattern [21].

Rigid-foldable surface. It is common practice to unfold completely a model and to look at the fold lines assembly which is called Crease Pattern (Figure 9). Considering now this assembly of straight folds and vertices, determining if it is continuously rigidfoldable remains a non-trivial task. This is mostly because one must ensure that the motion of each vertex is compatible to its neighbors [22, 23, 24]. Hence, many origami models are not rigid-foldable simply because some folding steps involve the bending of one or more facets. However, it is often possible to make these models rigid-foldable by introducing additional creases: Figure 10, [25, 26, 27]. Eventually, a rather broad range of origami models are covered by rigid folding simulations.

Rigid folding simulation. There are several approaches for implementing rigid folding simulations depending on the complexity of the folding pattern under consideration and also the fulfillment of rigid folding rules.

Some folded models may be achieved by a sequence of elementary folds. In this case, it is rather simple to model the sequence as it is done in the early work of Miyazaki [28]. As noticed by Balkcom and Mason [29], this approach is suitable for simple robotics and suggests a clear distinction between simple and complex folds. However, most folded models are complex: all hinges are moving at the same time and require more advanced simulations.

A first approach, suggested by Daniel Piker consists in relaxing the rigid folding constraints and minimizing a functional which mimics real physics in order to find a folded configuration. This methods called dynamic relaxation [30] is a rather flexible approach for simulating rigid origami and many other formfinding problems $[31,32]$ which is implemented as a plug-in of the scripting interface of Rhinoceros $3 \mathrm{D}^{\circledR}$ (Kangaroo Physics [33]). A possible difficulty with such an approach is that the converged solution found by the minimization process might not satisfy exactly the rigid folding constraints.

The second approach is based on the strict satisfaction of rigid folding constraints and the parametrization of the transformation with the folding angles. This is the framework presented by Belcastro and Hull [22] and followed by Mitani [34], Tachi [25, 35] and also Xi and Lien [36].

Because rigid folding is an extremely non-linear process combining multiple degrees of freedom, there are still interesting challenges to tackle. Having multiple degrees of freedom means that bifurcation leading to several compatible paths may be found during the folding process (a clear illustration is given in [37]) and managing self-contact introduces a sharp non-linearity.

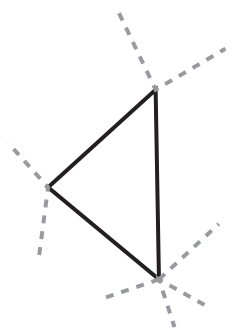

3 edges

0 sub-creases

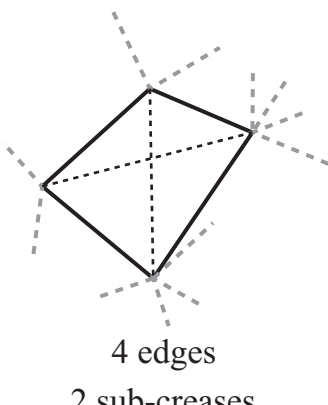

2 sub-creases

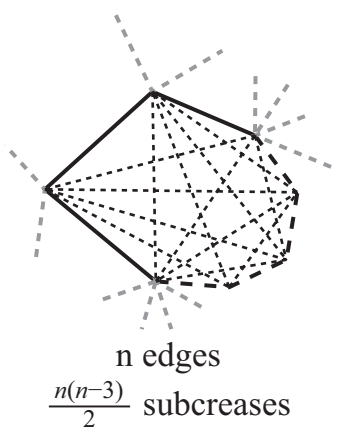

Figure 10. Each facet of a crease pattern may be divided by sub-creases in order to accommodate rigid foldability. 


\subsubsection{Curved folding}

A more general class of folds are curved folds. In this case the fold line is not straight. This rather simple generalization of folds actually generates a much more complex understanding of folding. An interesting review on research related to curved folds was performed by Demaine and Demaine [38].

Curved fold from mirroring operations. There is a first kind of curved fold which is simpler than general curved folds: curved folds generated by reflexions. Considering a developable surface, it is possible take its reflexion through a mirror (Figure 11). The image and the original surface may be matched along the line intersecting the mirror's plane and the surface. This line corresponds to the fold line and is therefore inscribed in a plane. For instance, an application of these concepts was presented by Mitani [39] in order to generate cylindrical shapes

Clearly, the surface is no more rigid-foldable. In addition, during the folding, both the fold line and each sides of the fold change their curvature. Actually, providing an efficient geometric description of these geometries is more difficult.

General curved fold. David Huffman is one of the first to explore deeper the potentialities of general curved folds. He created a series of inspiring models (Figure 12) revived by Demaine et al. [40]. A complete differential description of a general curved fold was derived by Duncan and Duncan [42]. It provides local relations to be satisfied between the curvatures of each sides of the fold and the curvature of the fold line itself. Numerical simulations of curved folds were early performed by Kergosien et al. [43]. Currently, new simulation tools are implemented directly into graphic programs which allows promising explorations of curved folds [44, 45]. However, curved folding large pieces is still a difficulty. The company Robofold ${ }^{\circledR}$ founded by Gregory Epps is specialized in curved
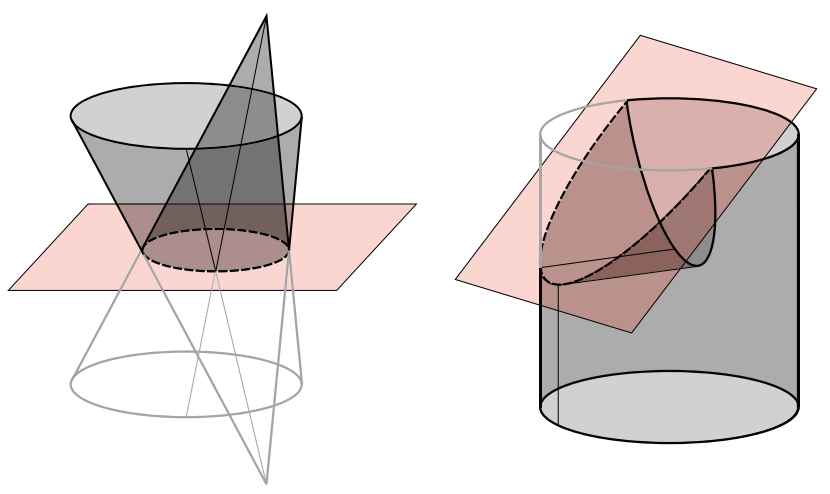

Figure 11. Curved folds from mirror operations; inspired by [12].

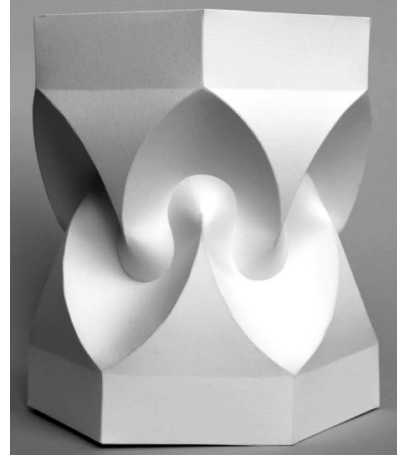

Figure 12. A curved fold with cusps designed by D. Huffman reproduced in [40].

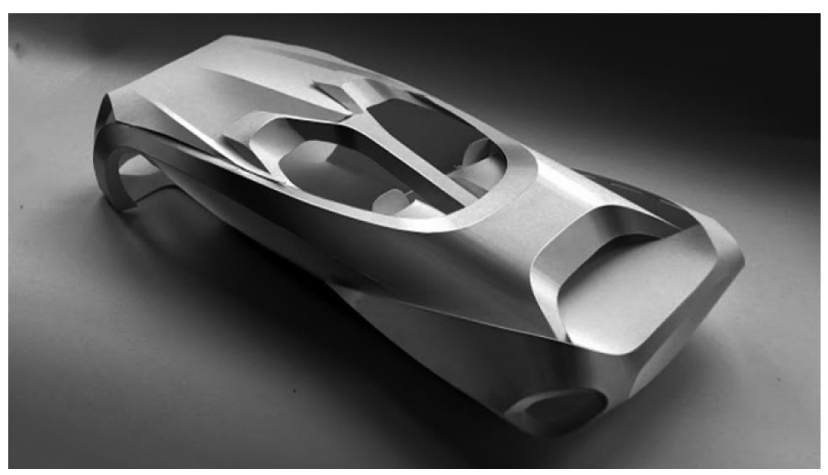

Figure 13. A developable car model designed by Kyungeun Ko for Bentley ${ }^{\mathrm{TM}}$ and prototyped by Robofold ${ }^{\circledR}[41]$.

folding with robots and offers new perspectives in this direction. Figure 13 presents a car model designed by Kyungeun Ko for the company Bentley ${ }^{\mathrm{TM}}$. The prototype was fabricated by Robofold ${ }^{\circledR}$.

Conical fold ( $d$-cone). The last singularities which may be source of investigation are developable cones (Figure 14). These singularities are always present in draperies [46, 47, 48, 49] and crumpled paper [50]. They appears also when stamping sheets of metal and Frey [51] showed that, driving their formation improves this forming process. Finally, this kind of folds have been mostly explored by designers such as Paul Jackson (Figure 15), however there are still few large scale applications.

\subsection{Form-finding with folds}

In order to target a given shape with folding and design new models, origamists use their deep experience of paper folding. Once the design is fixed they record the folding steps in diagrams. Nature is also a direct source of inspiration for models which presents some peculiar symmetry $[52,53]$ or correspond to a specific buckling pattern [54].

Only recently, some rational approaches for designing origami models where reviewed and also 


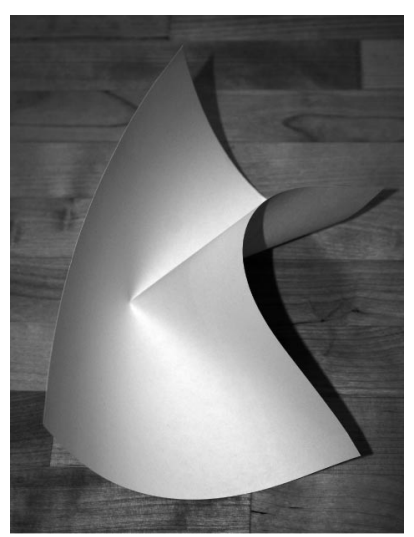

Figure 14. A d-cone in a sheet of paper.

suggested by Lang [20]. More systematically, Tachi [55] implemented a method which starts from a given polyhedral surface and builds a corresponding crease pattern (Figure 16).

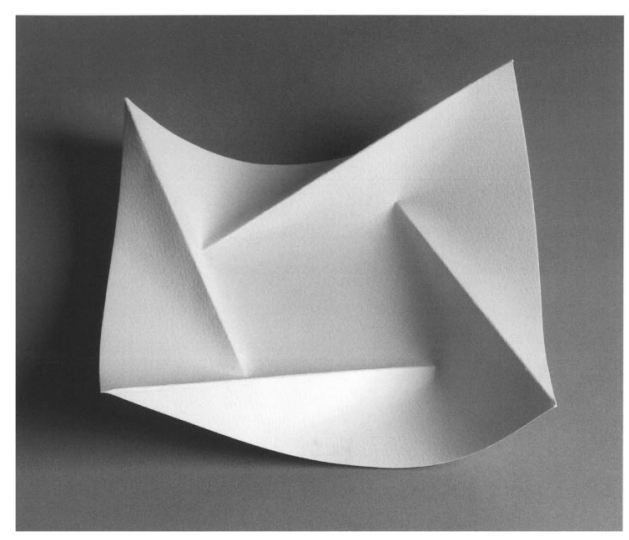

Figure 15. A dish designed P. Jackson [16].

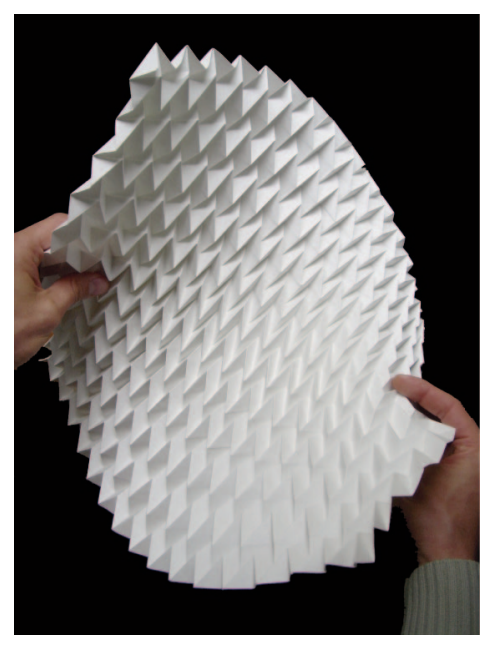

Figure 17. Large negative curvature accessible to Miura ori.

These approaches are considerable progress in terms of form-finding for the origami community. However they are not really suitable for applications in structures since they generally lead to complex crease patterns.

$3 D$ Folded tessellations. Folded tessellations (periodically folded patterns) might be considered as an interesting alternative to these approaches for designing folded structures since they are made of repeated elements (Figure 17).

Possibly, the first occurrence of folded tessellations is in fabric pleating. For instance a large collection of striking pleating dies are still in use at the small pleating company Les Ateliers Lognon. A very early field of application of these tessellations is packaging $[56,57,58]$ and one of the first structural applications is in folded cores for sandwich panels $[59,60,61,62]$.

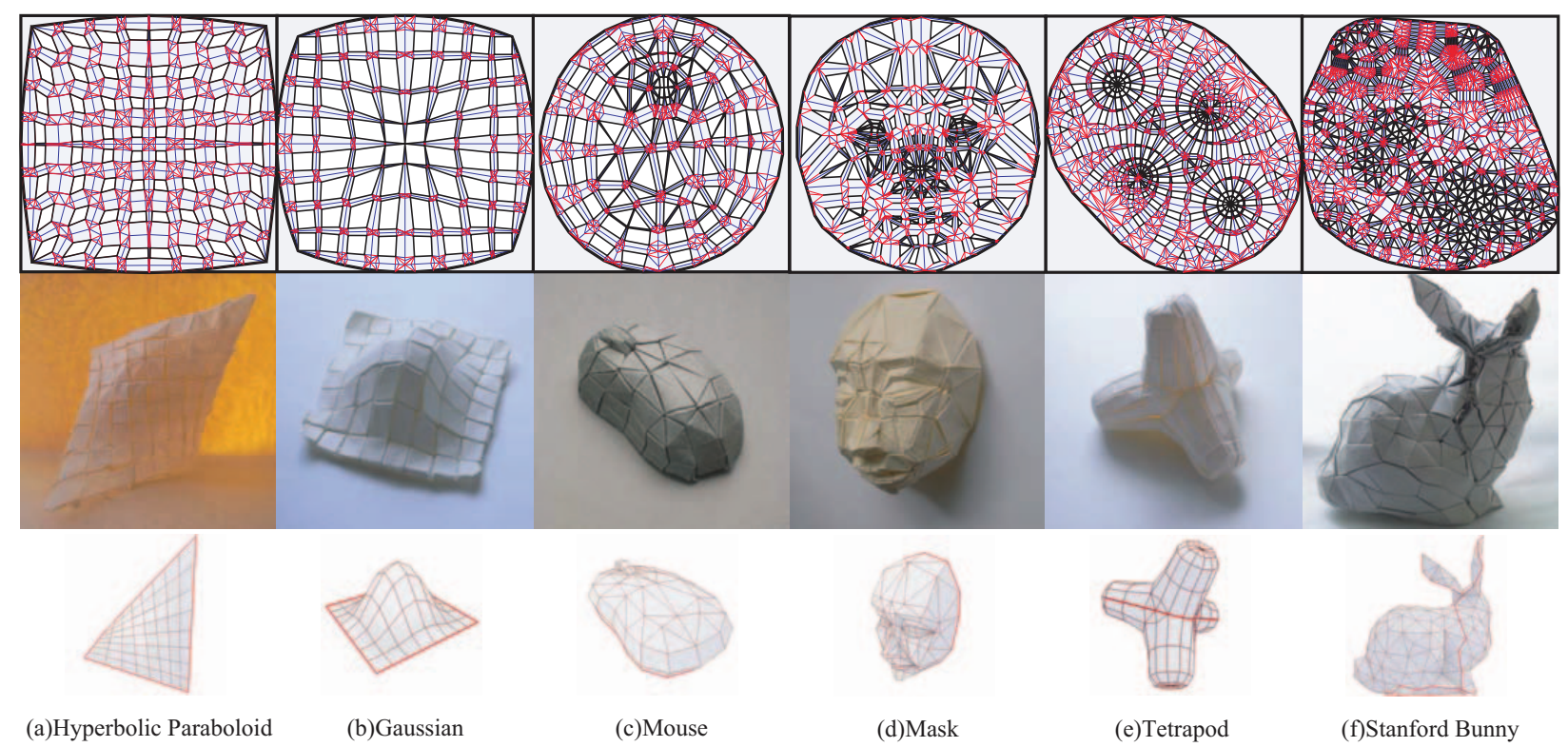

Figure 16. Crease patterns and their folded counterpart generated by Origamizer from Tachi [55] (with permission). 
Later, it rapidly became a specific area of origami, originated by Shuzo Fujimoto with flat foldable tesselations. David Huffman investigated many 3D tesselation as noticed by Davis et al. [63] and a recent monograph [64] provides a nice introduction to related folding techniques.

The main reason for a recent gain of interest are the accessible shapes of the originally "flat" tessellation. Large positive or negative curvatures of the average surface may be observed (Figure 17 and 18). Since, the original surface is only developable it seems remarkable that after micro-structuring it with a periodic pattern, new geometries become possible [65]. This is why these surfaces may be seen as "metasurfaces" in reference to meta-materials which exhibits non-conventional global properties thanks to a finely tuned micro-structure $[66,67,68,69,70,71]$.

The most investigated pattern is Miura ori ${ }^{1}$ (Figure 17). The homogenized behavior of the pattern alone was investigated $[66,67,69]$ but also when used as the core of a sandwich panel $[62,73,74,75]$. Many generalizations of the pattern were suggested and are also under investigation currently. For instance, Kling [76, 77] suggested a systematic approach to generate a family of foldable tessellations. Several works investigate how to perturb the pattern in order to get free forms $[78,79,80,81,82,83,37,84,85$, $86,87,88]$. An illustration is the design of a lampshade where Miura's pattern follows gradually a logarithmic spiral (Figure 19). Numerous applications are considered at different scales such as a compliant battery [89], heat exchanger [90], morphing structures $[91,92,93]$ and even active origami surfaces $[94,95,96]$.

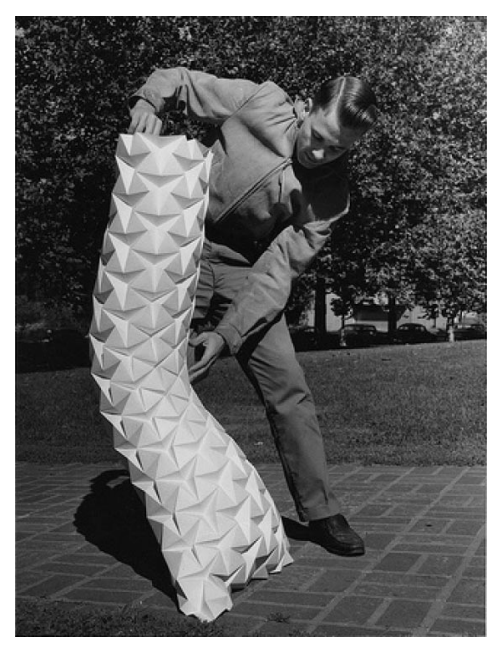

Figure 18. Large deformations of Ron Resch's pat-tern [72].

Ron Resch also made a landmark contribution investigating many new patterns [97, 72, 98]. Remarkably his most famous tesselation (Figure 18) offers very large deformations with both positive and negative double curvature. Resch's original intention was to use this pattern as a structural system [97]. Some of its mechanical properties were investigated in [69] and variations of the pattern was suggested by Tachi $[83,99]$. Many generalizations of these patterns may be found on the Internet.

Another case is the egg-box pattern. This tessellation is not developable, however it is strongly related to Miura ori and several works consider it as a metasurface. As an averaged surface, this pattern is able to generate both negative and positive double curvature $[100,101,92]$. The extension of this pattern in 3D was also homogenized [101, 102] and geometrical generalizations are under investigations [103, 104].
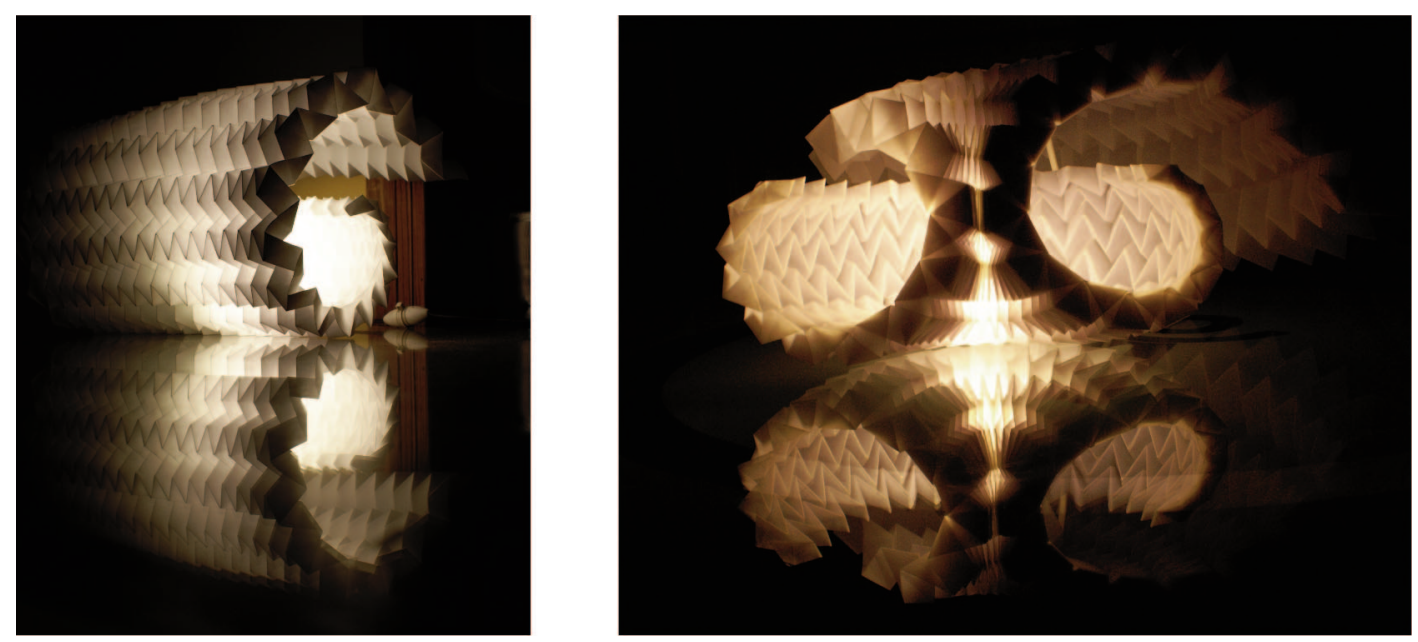

Figure 19. A folded lamp as a variation of Miura ori following a logarithmic spiral (Design A. Lebée).

${ }^{1}$ named after Koryo Miura who investigated this pattern [62] 
Eventually there is a very large number of patterns which have been suggested and have not yet been deeply investigated for structural applications. This offers interesting perspectives.

\section{FOLDS AS A STRUCTURE?}

Whereas there is an extremely broad diversity of folded shapes, real life applications are not so common. The main reason is that only pure geometry was devised till now. Depending on the targeted application, technological questions needs to be answered. Here are some examples.

In case a folding motion is sought, such as for a deployable structure, the thickness of the faces must be taken into account: when the fold is almost closed, there is contact between the faces before complete closure of the fold. This is a technological issue which is discussed for instance in $[82,105]$.

At small or medium scale, a manufacturing process based on folding techniques may be required to produce the folded shape. Because folds may involve fairly complex kinematics this may not be a simple task. There are several degrees of complexity when folding, starting from the simple fold - the kinematics of which is straightforward - to complex folds - where all folds may have motion at the same time [29, 106]. The case of folded cores is illustrating: the development of continuous manufacturing processes started in the sixties and is still an innovative field today [101]. Dealing with curved fold is even more challenging since all the surface is curved during the folding process. This requires to estimate spring-back of the folded shape with physical models.

Finally, because any application of a folded shape will endure some mechanical loadings, the question of the relation between folds and structures needs to be addressed.

The inevitable closure of a folded surface. Because folding is continuously transforming a flat surface in the 3D space, a folded shape is not a structure. It is a mechanism. This contradicts the common sense that folded or pleated structures are structurally efficient. Actually, the key for turning a folded surface into a structure consists in closing this mechanism. This closure is very often implicit in practical applications. Shedding the light on this central step helps understanding the mechanical behavior of folded surfaces. In order to do so, several mechanical modeling of folded surfaces are investigated. For each modeling, a relevant scale of application is illustrated and the corresponding closure pointed out.
Of course, the most simple way to turn a folded shape into a structure is making it not developable $[107,108,109]$. This is well illustrated by Gioia et al. [37] were the Miura ori is generalized to geometries which are partially foldable so that in each configuration the pattern presents some structural capacity. Another illustration is given by $\mathrm{Li}$ and Knippers [110], where vertices of the faceted dome are only reached by three fold lines. This prevents any relative rigid motion between the panels of the dome. However, preserving developability of the surface is an interesting feature and turning a folded shape into a structure is worth investigation.

\subsection{Folded surface as an assembly of rigid facets}

The most direct mechanical model is derived starting from the concept of rigid folding. This means having rigid facets with straight fold lines and perfect hinges. In that specific case, the closure of the folded surface consists simply in locking the kinematic degrees of freedom which were involved during the folding process. Since only relative rotation is allowed along fold lines, the corresponding internal forces which are transmitted along folds are resultants along the whole fold line. The only resultant which is not transmitted through the fold is the axial torque since it is the internal force working with the hinge rotation.

Since the rigid Miura ori is a 1 DOF mechanism, following this modelization, it is enough to lock the latter to get a structure (in addition to the usual 6 rigid DOF). For instance, this is done by locking one hinge or fixing two distant points. This specificity is one key of the success of this pattern. A map folded with this pattern opens easily with a single gesture [111].

For a structural engineer there are several difficulties with this approach. First, this modeling of internal forces implies a high degree of hyperstaticity when considering the assembly of rigid facets. Consequently, it is extremely difficult to figure out how internal forces are flowing inside the structure. In addition, internal forces are only resultant along the whole fold line. It gives thus a very poor description of the actual stress along the folding line. These difficulties inevitably confine deployable structures to gentle loadings and very often, the scaling of a fascinating paper model at the size of a whole building is simply impossible.

It is thus not surprising that the most relevant applications of deployable structures are space arrays and antennas $[112,113,114]$ thanks to the absence of gravity (Figure 20). 


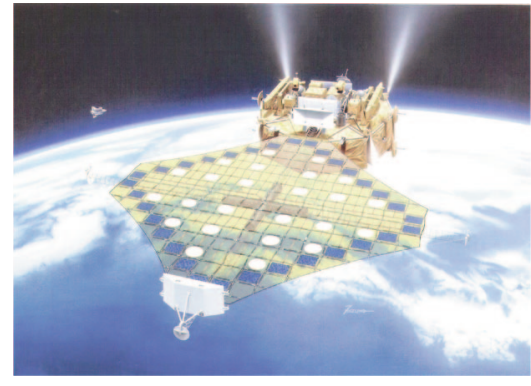

Figure 20. The space array designed by Miura and Natori [112].

There are still some attempts to take advantage of deployability in civil engineering. For instance, an interesting concept is Oricrete [115]. Concrete is cast on flat beds with a reinforcing fabric (Figure 21). Preforms following a crease pattern such as Yoshimura ori ensures that the device remains foldable once the concrete is hardened. The shape is deployed on site to its final 3D configuration and additional concrete is grouted in the hinges in order to lock the structure. The main technological challenge seems to perfectly control the motion on site, using adequate crane or levering tool.

\subsection{Folded surface as a shell}

A way of having a more detailed mechanical model of a folded shape is to assume it is an assembly of shells connected through elastic hinges. This kind of modeling is extremely common and allows finite element computations in mechanical engineering. The internal stresses are the classical shell stresses: the membrane stress $\boldsymbol{N}$, the bending moment $\boldsymbol{M}$ and the shear force $\boldsymbol{Q}$ (Figure 22). Notwithstanding the usual difficulties related to shell models, these internal stresses give a good description of the actual solicitations in the faces. The most simple modelization of the folds is to assume perfect hinges with a torsional spring related to the fold angle. With this description, almost all shell stresses may be equilibrated from one side of the fold to the other side
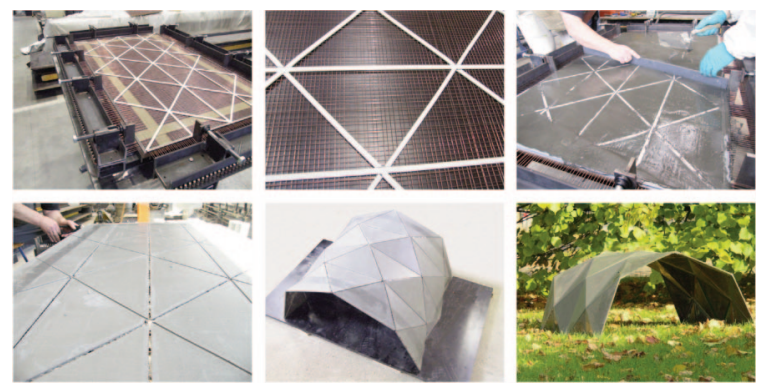

Figure 21. The fabrication and erection steps of a small scale oricrete [115].
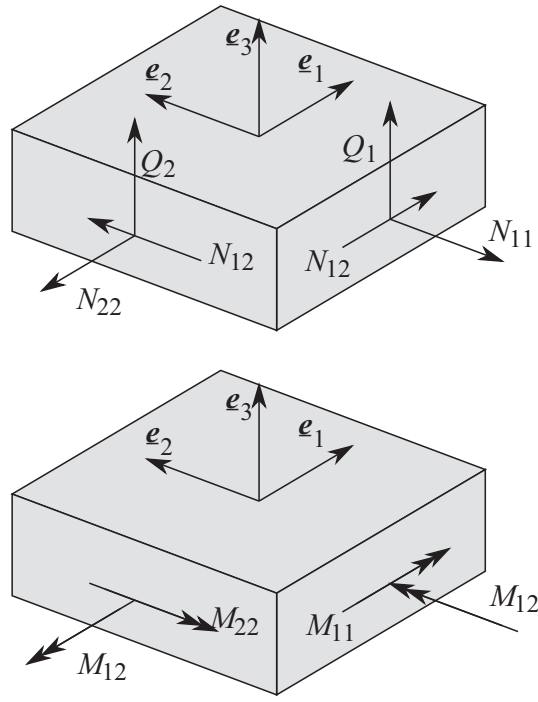

Figure 22. Plate generalized stress.

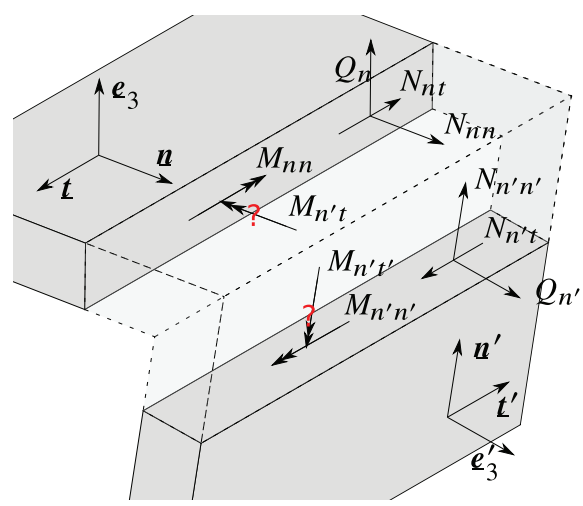

Figure 23. Generalized stresses transmitted along a fold line with a plate model.

(except the torsion normal to the fold line, Figure 23). Finally, with this modelization, the folded shape is an elastic solid and its closure consists simply in locking the 6 rigid DOF.

Whether this model or the previous one is relevant depends on the stiffness of the hinges compared to the slenderness of the faces [116]. With compliant hinges and thick faces, the rigid folding approach is more relevant and most of the deformation occurs in the folds. When the faces are thin with not so compliant hinges, the elasticity in the faces may no more be neglected. This is typically the case of folded paper.

Remarkably, in order to design a structure which can sustain larger loads it seems natural to have thicker faces. However, following the preceding observation, this choice concentrates the deformations in the folds. An interesting illustration of this trade off is given by Ibois [117] where a generalization of Miura ori was directly built with rather thick wood plates. The failure 

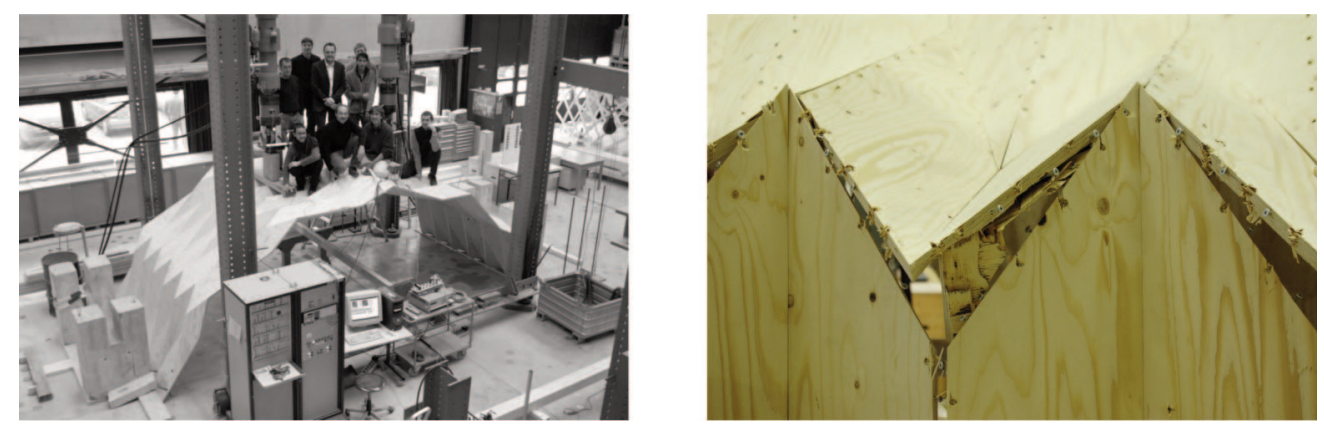

Figure 24. A wood shelter based on a generalization of Miura ori by [117] and the failure mechanism.

mechanism is completely focused in the hinges (Figure 24) and shows that the wood itself is loaded below its actual strength. Improving connection strength appears as a first answer and is an active field of research $[118,119,120,110]$. However, the observation that thickening the folded shape focuses the deformations in the folds points out a stringent limitation to structures derived from folds: either, the structure is thin, light and cannot sustain large loads, or it fails in the folds. This contradiction comes simply from the kinematic nature of folded shapes.

Whereas modeling a folded shape as a shell is relevant for the engineer since it provides the most detailed description of the solicitations in a folded structure, it seems that further investigations are required to capture the source of structural efficiency of pleated structures.

\subsection{Folded surface as a membrane}

Instead of thickening the faces, it is actually more interesting to investigate what happens when they become thinner. Taking the limit of a shell model for thin faces leads to a membrane model [121]. In that case, the only remaining internal force is the membrane stress (Figure 25). This reduction of internal forces has a drastic effect on the modeling of fold lines (Figure 26). Because there is no more bending moment, the fold line must be a hinge perfectly free to rotate. In addition, in absence of shear forces, the membrane stress normal to the fold line $N_{n n}$ cannot be equilibrated and thus must vanishes along this line ${ }^{2}$. The only membrane stress which is flowing through the fold line is the in-plane shear $N_{t n}$.

A direct conclusion of these observations might be that a fold actually weakens the surface since it reduces admissible stress flowing across the fold. This

\footnotetext{
${ }^{2}$ The same difficulty arises with free edges of thin shells: a ridge is often required in order to stiffen the edge and deviate the normal thrust.
}

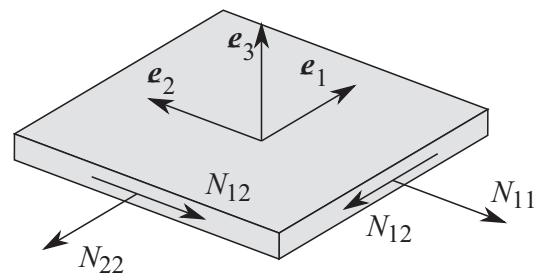

Figure 25. Membrane generalized stress.

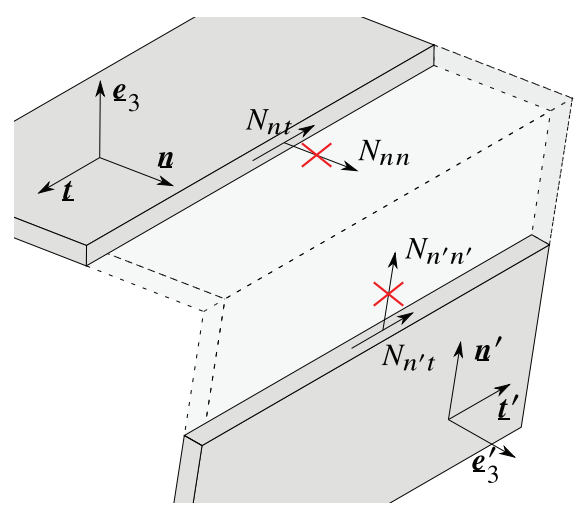

Figure 26. Generalized stresses transmitted along a fold line with a membrane model.

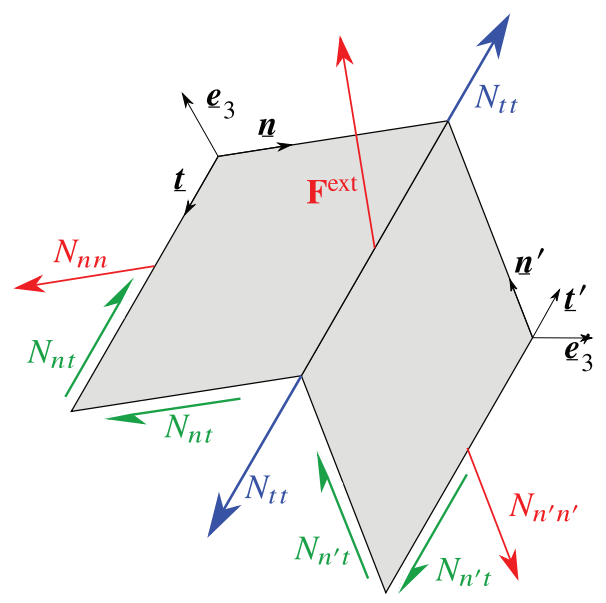

Figure 27. Systems of forces carried by a fold.

is not exactly the case. More precisely, the in-plane shear force-system is preserved (Figure 27, green arrows $N_{t n}$ and $N_{t^{\prime} n^{\prime}}$ ). The traction normal to the fold line vanishes, unless an additional force is added along 
the line in order to satisfy equilibrium (red system $N_{n n}$, $N_{n^{\prime} n^{\prime}}$ and $\mathbf{F}^{\text {ext }}$, Figure 27). Finally, the traction along the fold line is preserved and even improved in terms of buckling strength (blue system $N_{t t}$ and $N_{t^{\prime} t}$, Figure 27). Hence it is more accurate to say that the action of folding is creating anisotropy in the surface in terms of mechanical behavior [12]. Folding may be seen as choosing the strong direction for carrying loads and the weak direction for possible motion. Finally, a clever organization of folds leads to an efficient structural design.

Because the membrane model is the limit case when the surface is thin, it is also the one which is the most structurally efficient providing buckling is mitigated. This desirable structural behavior is recovered for the red system of forces (Figure 27) if a force is transferred along the fold line to another structural element. It is an interesting exercise to take a folded paper model which geometry has some architectural interest and to glue the right pieces of paper on the existing fold lines in order to get a rigid structure. This way of closing a folded shape is actually a key factor for the efficiency of folded cores.

Folded cores. Folded cores are folded tessellations, such as Miura ori, which are glued between two skins. The assembly is a rigid sandwich panel which is an efficient structural element in bending (Figure 28). It is the gluing of the skins which closes the structure and enables the transfer of membrane stress from the core to the skins. The resulting structural behavior in the case of Figure 28 is extremely similar to a Warren truss.

The faces of the folded pattern are mostly loaded with membrane stress when the sandwich panel is subjected to shear forces. Hence, modeling the faces as membranes enabled quite accurate estimations of the stress inside the panel and showed that in terms of transverse shear stiffness these panels are more efficient than honeycomb [62, 74].

Whereas folded cores are known since several decades, there was a recent regain of interest thanks to improved fabrication process and the possibility to

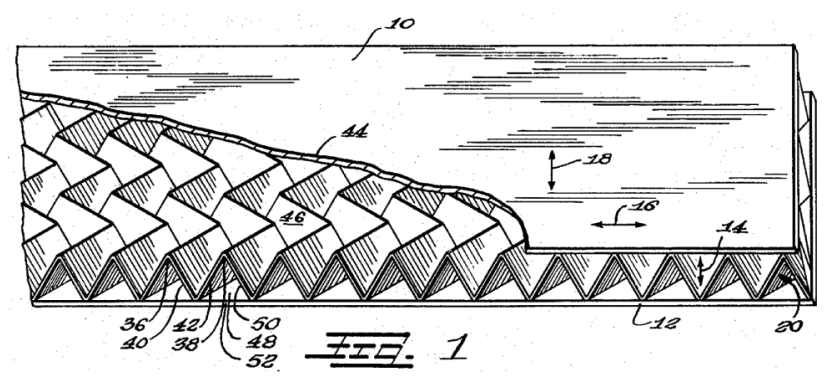

Figure 28. A sandwich panel with a Miura ori core [60]. ventilate the core $^{3}$. A large amount of experimental work was done in order to investigate the mechanical behavior of these cores $[122,123,124,125,126,127$, $128,129,130,131,132,133]$, as well as simulations $[125,134,74,75,135,136,137,138]$. The key issue remains the strength capacity of these cores. Since the failure occurs mostly because of faces buckling, it is extremely sensitive to geometric imperfections coming from the manufacturing process $[139,134]$.

The present review is focused on folded cores. However, there are many other manufacturing technologies for cellular cores. Among them some are based on both folding and cutting techniques (kirigami) [140, 141, 142, 143].

\subsection{Folded surface as a truss}

In case there is no wish to close the folded shape by adding structural elements, considering folds with a membrane model allows also another structural analogy. Since folding is making the surface stronger in compression along the fold direction (blue force system in Figure 27), any fold line may be considered as one bar of a truss [12]. Indeed, replacing the edges by three bars in a triangular facet leads to a rigid frame.

Facets with more edges may also be considered as in-plane rigid frames by adding the relevant triangulations exactly as done for sub-creases (Figure 10). Remarkably, this structural analogy is very different from the rigid-faces which was first investigated, however it provides a much clearer understanding of how folded shapes behave as structures. In addition, provided that all faces are correctly triangulated, the analogue truss follows exactly the same kinematics as the rigid-folding model. An illuminating example is suggested by De Temmerman et al. [144] where a foldable mobile shelter is designed, transforming literally the flat foldable paper model into a deployable truss (Figure 29). This analogy explains also why the Yoshimura pattern used by Chudoba et al. [115] is structurally efficient even if the surface is deployable (Figure 21).

\subsection{Pleats}

Considering a folded surface as a truss explains the central role played by pleats in structural design. In addition to larger capacity in the fold direction, pleating increases the structural thickness of the

${ }^{3}$ Honeycomb cells are closed once assembled in a sandwich panel. Successive take-off and landings of airplanes accumulate moist in the cells and cause unexpected and premature delamination of the panel. 
surface. These advantages are taught early in architecture schools [145] and interesting illustrations may be found in the classical work of Engel [146] (Section 30). Whereas deployable structures are

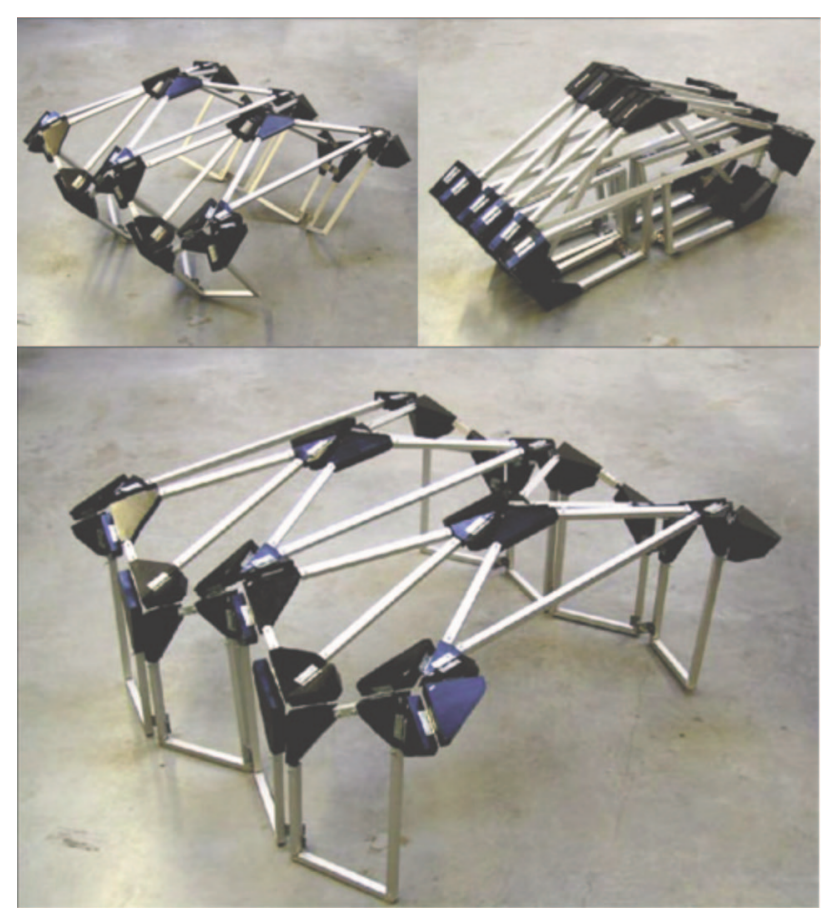

Figure 29. The truss analogue of a foldable paper model presented in De Temmerman et al. [144].
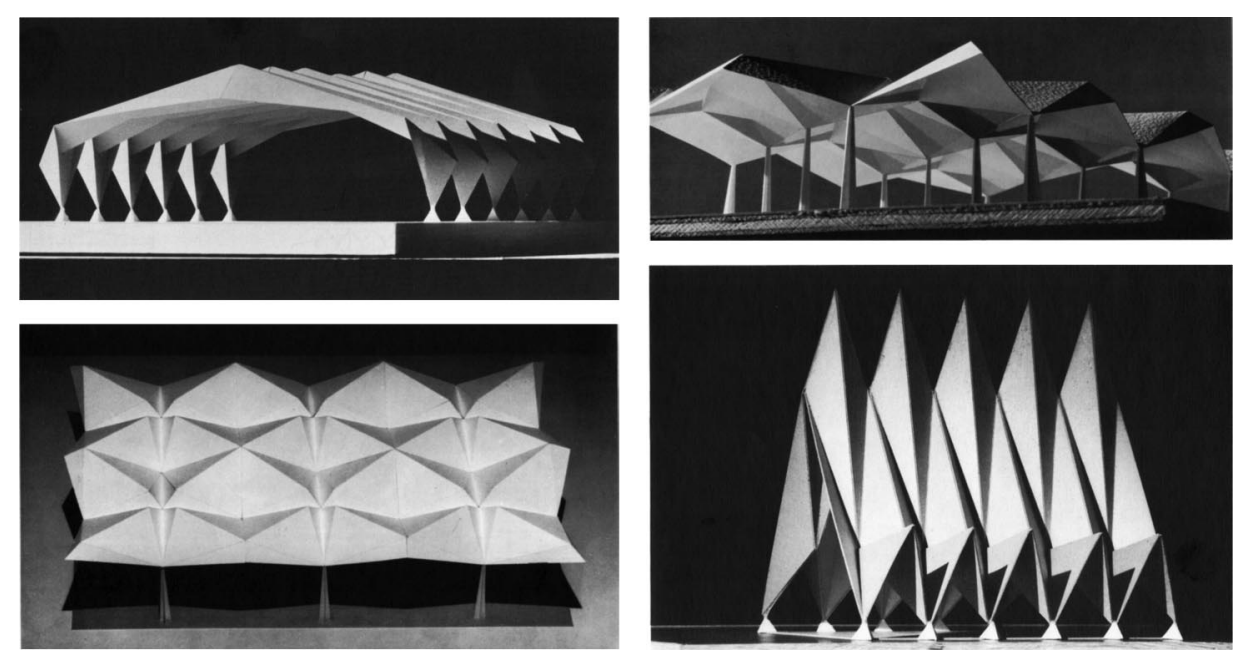

Figure 30. Heino Engel: Structure Systems [146].

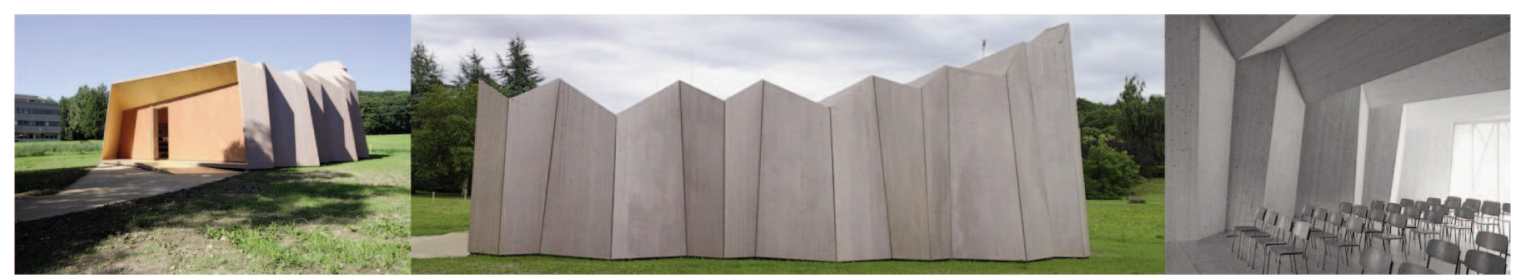

Figure 31. Chapel of Saint-Loup [147]. 

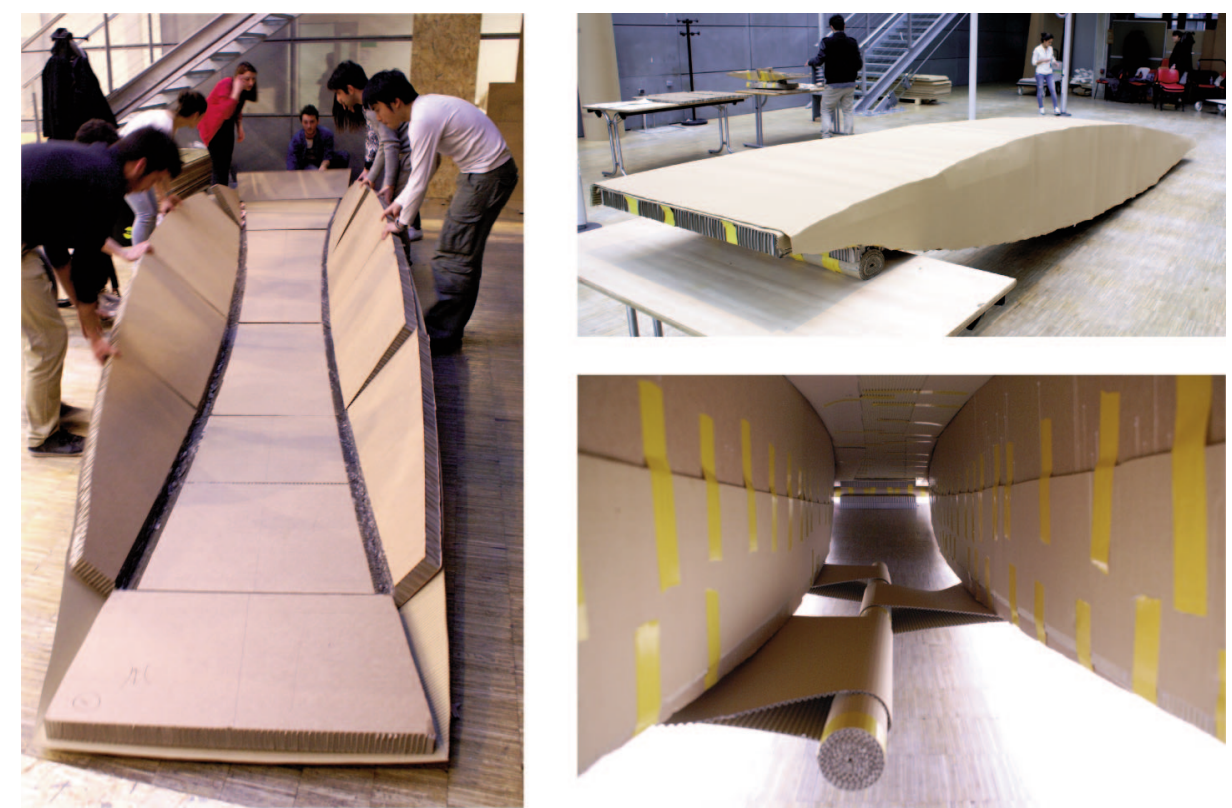

Figure 32. A foldable bridge made of corrugated cardboard and coardboard honeycomb. (Teachers: A. Lebée, M. Bernard, C. Chalumeaux, P. Lecomte; Students: M. Heinrich, N. Berrebbi, M. Kowalewski, A. Gauthier, S. L. Lee, J. Zagury, L. Gustin, L. Chassin, T. Biancone, R. Lévy).

Nationale des Ponts et Chaussées (Paris, France). During five days, they design, build and test a $6 \mathrm{~m}$ span bridge made of single face corrugated cardboard and paper honeycomb sandwich panels that must carry one pedestrian. Here, students managed to keep the foldability of the bridge which weighted approximately $54 \mathrm{~kg}$ and carried a $80 \mathrm{~kg}$ person walking. The closure of the fold is ensured by straps assembled by a cardboard rod under the bridge as illustrated in Figure 32.

Another challenging deployable bridge is suggested by Nagy et al. [149]. Again a clever use of the fold enables the preservation of the foldability in the transverse direction while still providing bending, shear and torsion strength.

\section{CONCLUSION}

While it is commonly accepted that there is a close link between folds and structure, a closer look at this question revealed that this link is mostly true but requires care. Considering folded shapes as the result of a form finding process showed that actually any surface may be reached. Hence for practical applications such as structures, simpler folds and possibly folded tessellations may be considered as good candidates.

Notwithstanding the fabrication difficulty, folded shapes are originally mechanisms and their structural behavior requires appropriate mechanical models for an efficient design. It appeared that the most efficient solicitation for a folded shape is in the plane of the facets (membrane model). However, this mechanical behavior is obtained only in specific directions of the fold. If this is not the case, it seems more relevant to consider the folded shape as a truss in a preliminary design stage.

There are still rather few full-scale application of folding concepts which are real structures. However, the recent combination of new graphical tools and new digitized fabrication process opens a wide perspective for promising applications.

\section{REFERENCES}

[1] Hannes C. Schniepp, Konstantin N. Kudin, Je-Luen Li, Robert K Prud'homme, Roberto Car, Dudley A Saville, and Ilhan A Aksay. Bending properties of single functionalized graphene sheets probed by atomic force microscopy. ACS Nano, 2(12): 2577-2584, 2008. ISSN 1936-086X. doi: 10.1021/nn800457s.

[2] Steven Cranford, Dipanjan Sen, and Markus J. Buehler. Meso-origami: Folding multilayer graphene sheets. Appl. Phys. Lett., 95(12):123121, 2009. ISSN 00036951. doi: 10.1063/1.3223783. URL http://link.aip.org/link/APPLAB/ v95/i12/p123121/s1\&Agg=doi.

[3] Hidetoshi Kobayashi, B. Kresling, and J. F. V. Vincent. The geometry of unfolding tree leaves. Proc. R. Soc. B Biol. Sci., 265(1391):147-154, January 1998. ISSN 0962-8452. doi: 10.1098/rspb.1998.0276. URL http: //rspb.royalsocietypublishing.org/cgi/doi/10.1098/rspb.1 998.0276.

[4] Dominique Buisson. Manuel pratique d'origami. Celiv, Paris, 1990. ISBN 2-86535-124-6.

[5] Toshikazu Kawasaki, Ryuhei Uehara, Tomohiro Tachi, and Jun Maekawa, editors. The 6th International Meeting 
on Origami in Science, Mathematics and Education. The 6OSME Organizing committee, 2014. URL http:// origami.gr.jp/6osme/.

[6] Edwin A Peraza-Hernandez, Darren J Hartl, Richard J Malak Jr, and Dimitris C Lagoudas. Origami-inspired active structures: a synthesis and review. Smart Mater. Struct., 23(9):094001, 2014. ISSN 0964-1726. doi: 10.1088/0964-1726/23/9/094001. URL http://stacks. iop.org/0964-1726/23/i=9/a=094001?key=crossref. 6226c53c3ab2492e5686c0d4be08ea2e.

[7] Stewart, I., 2007, Mathematics: some assembly needed. Nature, 448(7152), p. 419.

[8] S. Felton, M. Tolley, Erik D. Demaine, D. Rus, and R. Wood. A method for building self-folding machines. Science, 345(6197):644-646, 2014. ISSN 0036-8075. doi: 10.1126/science.1252610. URL http://www. sciencemag.org/cgi/ doi/10.1126/science.1252610.

[9] Arzu Gönenç Sorguç, Ichiro Hagiwara, and Semra Arslan Selçuk. Origamics In Architecture: A Medium Of Inquiry Or Design In Architecture. METU J. Fac. Archit., 26(2):235-247, December 2009. ISSN 02585316. doi: 10.4305/METU.JFA. 2009.2.12. URL http://jfa.arch. metu.edu.tr/archive/0258-5316/2009/cilt26/sayi_2/235247.pdf.

[10] David Dureisseix. An Overview of Mechanisms and Patterns with Origami. Int. J. Sp. Struct., 27(1):1-14, March 2012. ISSN 0266-3511. doi: 10.1260/02663511.27.1.1. URL http://multi-science.metapress.com/ openurl.asp? genre=article\&id=doi:10.1260/0266-3511. 27.1.1.

[11] Nenad Sekularac, Jelena Ivanovic-Sekularac, and Jasna Cikic-Tovarovic. Folded structures in modern architecture. Facta Univ. - Ser. Archit. Civ. Eng., 10(1):1-16, 2012. ISSN 0354-4605. doi: 10.2298/ FUACE1201001S. URL http://www.doiserbia.nb.rs/ Article.aspx?ID=0354-46051201001S.

[12] Jean-Marie Delarue. Plis, Règles Géométriques et Principes Structurants. Ecole D'architecture ParisVillemin, 1997.

[13] Helmut Pottmann, Alexander Schiftner, Pengbo Bo, Heinz Schmiedhofer, Wenping Wang, Niccolo Baldassini, and Johannes Wallner. Freeform surfaces from single curved panels. ACM Trans. Graph., 27(3):1, 2008. ISSN 07300301. doi: 10.1145/1360612.1360675.

[14] Vincent Borrelli, Saïd Jabrane, Francis Lazarus, and Boris Thibert. Flat tori in three-dimensional space and convex integration. Proc. Natl. Acad. Sci. U. S. A., 109(19):7218-23, May 2012. ISSN 1091-6490. doi: 10.1073/pnas. 1118478109. URL http://www.pnas.org/ content/109/19/7218.shorthttp://www.pubmedcentral.nih. gov/articlerender.fcgi ?artid=3358891\&tool=pmcentrez\& rendertype $=$ abstract.

[15] Jiangmei Wu. Torus, 2013. URL http://www.foldedlightart.com/\#!torus/cfv8.

[16] Paul Jackson. Folding techniques for designers: from sheet to form. Laurence King Pub., London, 2011. ISBN 97818566972171856697215.

[17] F. Lechenault and M. Adda-Bedia. Origami switches: generic bistability in creased sheets. preprint, 2015.

[18] David A. Huffman. Curvature and creases: a primer on paper. IEEE Trans. Comput., C-25(10):1010-1019, October 1976. ISSN 0018-9340. doi: 10.1109/ TC.1976.1674542. URL http://ieeexplore.ieee.org/lpdocs/ epic03/wrapper. htm?arnumber=1674542.
[19] Koryo Miura. A Note on Intrinsic Geometry of Origami. In Res. Pattern Form., pages 91-102. R. Takaki, ktk scient edition, 1994.

[20] Robert J. Lang. Origami design secrets : mathematical methods for an ancient art. A.K. Peters, Natick MA, 2003. ISBN 15688119429781568811949.

[21] Robert J. Lang. Crease Pattern Gallery. URL http://www.langorigami.com/art/creasepatterns/ creasepatterns_gallery.php.

[22] Sarah-Marie Belcastro and Thomas C. Hull. Modelling the folding of paper into three dimensions using affine transformations. Linear Algebra Appl., 348(1-3):273282, 2002. ISSN 00243795. doi: 10.1016/S00243795(01)00608-5.

[23] Hellmuth Stachel. A kinematic approach to Kokotsakis meshes. Comput. Aided Geom. Des., 27(6):428-437, 2010. ISSN 01678396. doi: 10.1016/j.cagd.2010.05.002. URL http://dx.doi.org/10.1016/j.cagd.2010.05.002.

[24] Weina Wu and Zhong You. Modelling rigid origami with quaternions and dual quaternions. Proc. R. Soc. A Math. Phys. Eng. Sci., 466(2119):2155-2174, February 2010. ISSN 1364-5021. doi: 10.1098/rspa.2009.0625. URL http: //rspa.royalsocietypublishing.org/cgi/doi/10.1098/ rspa.2009.0625.

[25] Tomohiro Tachi. Simulation of Rigid Origami. In 4th Int. Meet. Origami Sci. Technol., 2006.

[26] Erik D. Demaine, Martin L. Demaine, Vi Hart, Gregory N Price, and Tomohiro Tachi. (Non)existence of Pleated Folds: How Paper Folds Between Creases. Abstr. from 7th Japan Conf. Comput. Geom. Graphs (JCCGG 2009), page 19, June 2009. URL http://arxiv.org/abs/0906.4747.

[27] A. P. Korte, E. L. Starostin, and G. H. M. van der Heijden. Triangular buckling patterns of twisted inextensible strips. Proc. R. Soc. A Math. Phys. Eng. Sci.,

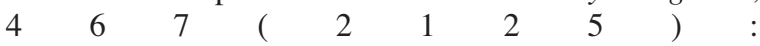
285-303, June 2010. ISSN 1364-5021. doi: 10.1098/ rspa.2010.0200.URL http://rspa.royalsocietypublishing. org/cgi/doi/10.1098/rspa.2010.0200.

[28] Shin-ya Miyazaki. An Origami Playing Simulator in the Virtual Space. J. Vis. Comput. Animat., 7(March 1995):25-42, 1996. ISSN 10498907. doi: 10.1002/ (SICI)1099-1778(199601)7:1<25::AID-VIS 134> 3.0.CO;2-V.

[29] D. J. Balkcom and M. T. Mason. Robotic origami folding. Int. J. Rob. Res., 27(5):613-627, May 2008. ISSN 02783649. doi: 10.1177/0278364908090235. URL http:// ijr.sagepub.com/cgi/doi/10.1177/278364908090235.

[30] S. A. Day. An Introduction to Dynamic Relaxation. Eng., 29:218-221, 1965.

[31] Michael Barnes. Form and stress engineering of tension structures. Struct. Eng. Rev., 6(3), 1994. URL http://opus. bath.ac.uk/33733/.

[32] Cyril Douthe and Olivier Baverel. Design of nexorades or reciprocal frame systems with the dynamic relaxation method. Comput. \& Struct., 87(21-22):1296-1307, 2009. ISSN 0045-7949. URL http://www.sciencedirect.com/ science/ article/pii/S0045794909001862.

[33] Daniel Piker. Kangaroo Physics, 2015. URL http://www.food4rhino.com/project/kangaroo?etx.

[34] Jun Mitani. ORIPA: Origami Pattern Editor, 2005. URL http://mitani.cs.tsukuba.ac.jp/oripa/.

[35] Tomohiro Tachi. Geometric considerations for the design of rigid origami structures. In Assoc. Shell Spat. Struct., 
2010. URL http://www.tsg.ne.jp/tT/cg/DesignOfRigid OrigamiStructures_tachi_IASS2010.pdf.

[36] Zhonghua Xi and Jyh-Ming Lien. Folding rigid origami with closure constraints. In ASME 2014 Int. Des. Eng. Tech. Conf. Comput. Inf. Eng. Conf., 2014. doi: 10.1115/DETC2014-35556.

[37] Francesco Gioia, David Dureisseix, René Motro, and Bernard Maurin. Design and Analysis of a Foldable/Unfoldable Corrugated Architectural Curved Envelop. J. Mech. Des., 134(3):031003, 2012. ISSN 10500472. doi: 10.1115/1.4005601. URL http://link. aip.org/link/JMDEDB/v134/i3/p031003/s1\&Agg=doi.

[38] Erik D. Demaine and Martin L. Demaine. Curved Crease Folding a Review on Art, Design and Mathematics. In Proc. IABSE-IASS Symp. Taller, Longer, Light. (IABSE-IASS 2011), 2011.

[39] Jun Mitani. Column-shaped origami design based on mirror reflections. In 15th Int. Conf. Geom. Graph., 2012.

[40] Erik D. Demaine, Martin L. Demaine, and Duks Koschitz. Reconstructing David Huffman's Legacy in Curved-Crease Folding. In th Int. Conf. Origami Sci. Math. Educ., 2010.

[41] Kyungeun Ko. Bentley and Kyungeun KO, 2013. URL http://www.robofold.com/make/consultancy/projects/ bentley-and-kyungeun-ko.

[42] J. P. Duncan and J. L. Duncan. Folded Developables. Proc. R. Soc. Lond. A. Math. Phys. Sci., 383(1784):191205, September 1982. ISSN 0080-4630. doi: 10.1098/rspa.1982.0126. URL http://links.jstor.org/ sici?sici=0080-4630(19820908)383:1784<191:FD> 2.0.CO;2-Bhttp://rspa.royalsocietypublishing.org/ cgi/doi/ 10.1098/rspa.1982.0126.

[43] YL Kergosien, H Gotoda, and T.L. Kunii. Bending and creasing virtual paper. IEEE Comput. Graph. Appl., 14(1):40-48, January 1994. ISSN 0272-1716. doi: 10.1109/38.250917. URL http://ieeexplore.ieee.org/xpls/ abs_all.jsp? arnumber=250917http://ieeexplore.ieee.org/ lpdocs/epic03/wrapper.htm?arnumber=250917.

[44] Martin Kilian, Simon Flöry, Zhonggui Chen, Niloy J. Mitra, Alla Sheer, and Helmut Pottmann. Curved folding. In ACM SIGGRAPH 2008 Pap. - SIGGRAPH '08, page 1, New York, New York, USA, 2008. ACM Press. ISBN 9781450301121. doi: 10.1145/1399504.1360674. URL http://dl.acm.org/citation.cfm?id=1360674http://portal.a cm.org/ citation.cfm?doid=1399504.1360674.

[45] Tomohiro Tachi and Gregory Epps. Designing One-DOF Mechanisms for Architecture by Rationalizing Curved Folding. In Int. Symp. Algorithmic Des. Archit. Urban Des., 2011. URL http://www.tsg.ne.jp/tT/cg/Rigid OrigamiCurvedFoldingTachiEppsALGODE2011.pdf.

[46] M. Ben Amar and Y Pomeau. Crumpled paper, 1997. ISSN 1364-5021.

[47] Enrique Cerda and Francisco Melo. Conical dislocations in crumpling. Nature, 401(September), 1999. doi: $10.1038 / 43395$.

[48] E Cerda, L Mahadevan, and J M Pasini. The elements of draping. Proc. Natl. Acad. Sci. U. S. A., 101(7):18061810, 2004. ISSN 0027-8424. doi: 10.1073/pnas. 0307160101.

[49] Enrique Cerda and L. Mahadevan. Confined developable elastic surfaces: cylinders, cones and the Elastica. Proc. R. Soc. A Math. Phys. Eng. Sci., 461(2055):671-700, March 2005. ISSN 1364-5021. doi: 10.1098/rspa.2004.
1371. URL http://rspa.royalsocietypublishing.org/ cgi/doi/10.1098/rspa.2004.1371http://dx.doi.org/10.1098/ rspa.2004.1371.

[50] TA A Witten. Stress focusing in elastic sheets. Rev. Mod. Phys., 79(2):643-675, 2007. doi: 10.1103/RevModPhys. 79.643. URL http://rmp.aps.org/abstract/RMP/v79/i2/ p643_1.

[51] William H. Frey. Modeling buckled developable surfaces by triangulation. Comput. Des., 36(4):299-313, February 2004. ISSN 00104485. doi: 10.1016/S00104485(03)00105-2. URL http://www.sciencedirect.com/ science/article/ pii/S0010448503001052.

[52] Taketoshi Nojima. Origami Modelling of Functional Structures based on Organic Patterns. Nature, 1996.

[53] Taketoshi Nojima. Modelling of Folding Patterns in Flat Membranes and Cylinders by Using Origami., 2000. ISSN 0387-5024.

[54] Giles W. Hunt and Ichiro Ario. Twist buckling and the foldable cylinder: An exercise in origami. Int. J. Non. Linear. Mech., 40(6):833-843, 2005. ISSN 00207462. doi: 10.1016/j.ijnonlinmec.2004.08.011.

[55] Tomohiro Tachi. Origamizing polyhedral surfaces. IEEE Trans. Vis. Comput. Graph., 16(2):298-311, 2010. ISSN 10772626. doi: 10.1109/TVCG.2009.67.

[56] M Newton. Paper for packing Lining and other purposes, December 1880. URL http://www.google.com/patents/ US235449.

[57] H Ichikawa. Reinforced composite corrugate body, US Patent: US 5,314, 738, 1994.

[58] E.A. Elsayed and B. Basily. A continuous folding process for sheet materials. Int. J. Mater. Prod. Technol., 21(1/2/3): 217, 2004. ISSN 0268-1900. doi: 10.1504/IJMPT.2004.004753. URL http://www. inderscience.com/link.php?id=4753http://inderscience. metapress.com/index/unkcqijh8g2p9f40.pdf.

[59] H Hochfeld. Process and Machine for Pleating pliable materials, US2901951, 1959.

[60] Edward Rapp. Sandwich-type structural element, US2963128, 1960.

[61] L V Gewiss. Procédé et machines pour le façonnage de structures chevronnées et de structures dérivant des structures chevronnées, 1968.

[62] Koryo Miura. Zeta-Core Sandwich - Its Concept and Realization. ISAS Rep., 37(6):137-164, 1972. ISSN 03721418. URL http://ci.nii.ac.jp/naid/110001101664/en/.

[63] Eli Davis, Erik D. Demaine, Martin L. Demaine, Jennifer Ramseyer, and Origami Tessellations. Reconstructing David Huffman's Origami Tessellations 1.J.Mech.Des., 135(11):111010, October 2013. ISSN 1050-0472. doi: 10.1115/ 1.4025428. URL http://mechanicaldesign. asmedigitalcollection.asme.org/article.aspx?doi=10.111/ 1.4025428 .

[64] Eric Gjerde. Origami tessellations: awe-inspiring geometric designs. A K Peters, Wellesley, Mass., 2009. ISBN 978156881451315688145189781579909796 1579909795.

[65] Keith A. Seffen. Compliant shell mechanisms, Philosophical Transactions of the Royal Society A: Mathematical, Physical and Engineering Sciences, 370(1965): 2010-2026, 2012

[66] Mark Schenk and Simon D Guest. Geometry of Miurafolded metamaterials. Proc. Natl. Acad. Sci. U. S. A., 110(9): 3276-81, February 2013. ISSN 1091-6490. doi: 10.1073/pnas.1217998110. URL http://www.ncbi. nlm.nih.gov/pubmed/23401549. 
[67] Zhiyan Y. Wei, Zengcai V. Guo, Levi Dudte, Haiyi Y. Liang, and L. Mahadevan. Geometric Mechanics of Periodic Pleated Origami. Phys. Rev. Lett., 110(21):215501, November 2013. ISSN 0031-9007. doi: 10.1103/PhysRevLett.110.215501. URL http://arxiv.org/ abs/1211.6396http://link.aps.org/doi/10.1103/PhysRevL ett.110.215501.

[68] Zhong You. Folding structures out of flat materials. Science, 345(6197):623-624, 2014. ISSN 0036-8075. doi: 10.1126/science.1257841. URL http:// www.sciencemag.org/cgi/doi/10.1126/science.1257841.

[69] Cheng Lv, Deepakshyam Krishnaraju, Goran Konjevod, Hongyu Yu, and Hanqing Jiang. Origami based Mechanical Metamaterials. Sci. Rep., 4:5979, January 2014. ISSN 2045-2322. doi: 10.1038/srep05979. URL http://www.pubmedcentral.nih.gov/articlerender.fcgi?arti $\mathrm{d}=4124469 \&$ tool $=$ pmcentrez \& rendertype $=$ abstracthttp://www.nature.com/srep/2014/140807/srep05 979/full/srep05979.html.

[70] J. L. Silverberg, a. a. Evans, L. McLeod, R. C. Hayward, Thomas C. Hull, C. D. Santangelo, and I. Cohen. Using origami design principles to fold reprogrammable mechanical metamaterials. Science, 345(6197): 647-650, 2014. ISSN 0036-8075. doi: 10.1126/science. 1252876. URL http://www.sciencemag.org/cgi/doi/ $10.1126 /$ science. 1252876 .

[71] Jesse L Silverberg, Jun-hee Na, Arthur A Evans, Bin Liu, Thomas C. Hull, Christian D Santangelo, Robert J. Lang, Ryan C Hayward, and Itai Cohen. Origami structures with a critical transition to bistability arising from hidden degrees of freedom. Nat. Mater., 14(March): 1-5, 2015. doi: 10.1038/NMAT4232.

[72] Ronald D. Resch and Hans Christiansen. The design and analysis of kinematic folded-plate systems. In Proc. Symp. folded plates Prism. Struct. Int. Assoc. shell Struct., Vienna, 1970.

[73] Koryo Miura. New structural form of sandwich core, 1975. ISSN 0021-8669.

[74] Arthur Lebée and Karam Sab. Transverse shear stiffness of a chevron folded core used in sandwich construction. Int. J. Solids Struct., 47(18-19):2620-2629, September 2010. ISSN 00207683. doi: 10.1016/j.ijsolstr.2010.05. 024. URL http://www.sciencedirect.com/science/ article/B6VJS-506RCW3-1/2/ 70a945e9ed2d9b63a1eb 91826f306304http://linkinghub.elsevier.com/retrieve/pii/ S0020768310002027.

[75] Arthur Lebée and Karam Sab. Homogenization of thick periodic plates: Application of the Bending-Gradient plate theory to a folded core sandwich panel. Int. J. Solids Struct., 49(19-20):2778-2792, October 2012. ISSN 00207683. doi: 10.1016/j.ijsolstr.2011.12.009. URL http:// linkinghub.elsevier.com/retrieve/pii/S0020768311004173.

[76] D H Kling. Doubly periodic flat surfaces in three-space. PhD thesis, Rutgers Univ., October 1997.

[77] D H Kling. Paterning technology for folded sheet structures, US 6,935, 997, 2005.

[78] R M Czaplicki. Cellular core structure providing gridlike bearing surfaces on opposing parallel planes of the formed core, US 5, 028, 474, 1991.

[79] Charles Hoberman. Curved pleated sheet structures, 1993. URL http://www.google.com/patents/US5234727.
[80] Tomohiro Tachi. Generalization of rigid-foldable quadrilateral-mesh origami. In Proc. IASS Symp., pages 173-179, Alfonso XII, 3, Madrid, 28014, Spain, 2009. Int. Association for Shell and Spatial Structures.

[81] Hellmuth Stachel. Remarks On Miura-Ori, A Japanese Folding Method. In Int. Conf. Eng. Graph. Des., pages 2-5, 2009 .

[82] Martin Trautz and Arne Kunstler. Deployable folded plate structures-folding patterns based on 4-foldmechanism using stiff plates. In A Domingo and C Lazaro, editors, Proc. Int. Assoc. Shell Spat. Struct. Symp. 2009, Val. Evol. Trends Des. Anal. Constr. Shell Spat. Struct., 2009. URL http://trako.arch.rwth-

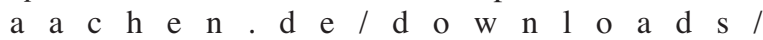
PAP60kuenstler.pdf.

[83] Tomohiro Tachi. Freeform variations of origami. J. Geom. Graph., 14(2):203-215, 2010. ISSN 14338157.

[84] Andreas Falk, Peter Von Buelow, and Poul Henning Kirkegaard. Folded plate structures as building envelopes. In World Conf. Timber Eng., Auckland, 2012. URL http://www.timberdesign.org.nz/WCTE2012.cfm/ view/459/parent/47.

[85] Valentina Beatini and Koray Korkmaz. Shapes of Miura Mesh Mechanism with Mobility One. Int. J. Sp. Struct., 28(2): 101-114, 2013. ISSN 0266-3511. doi: 10.1260/0266-3511.28.2.101. URL http://multi-science. metapress.com/openurl.asp?genre=article $\& \mathrm{id}=$ doi: 10.12 60/0266-3511.28.2.101.

[86] Yves Klett. Realtime Rigid Folding Algorithm for Quadrilateral-Based 1-DOF Tessellations. In Vol.6B 37th Mech. Robot. Conf., page V06BT07A031. ASME, August 2013. ISBN 978-0-7918-5594-2. doi: 10.1115/ DETC2013-12659. URL http://proceedings.asme digitalcollection.asme.org/proceeding.aspx?doi=10.1115/ DETC2013-12659.

[87] Joseph M. Gattas, Weina Wu, and Zhong You. MiuraBase Rigid Origami: Parameterizations of First-Level Derivative and Piecewise Geometries. J. Mech. Des., 135(11):111011, October 2013. ISSN 1050-0472. doi: 10.1115/1.4025380. URL http://mechanicaldesign.asme digitalcollection.asme.org/article.aspx?doi=10.1115/1.40 25380.

[88] Pooya Sareh and Simon Guest. A Framework for the Symmetric Generalisation of the Miura-ori. Int. J. Sp. Struct., in-press, 2015.

[89] Zeming Song, Teng Ma, Rui Tang, Qian Cheng, Xu Wang, Deepakshyam Krishnaraju, Rahul Panat, Candace K. Chan, Hongyu Yu, and Hanqing Jiang. Origami lithium-ion batteries. Nat. Commun., 5:1-6, 2014. ISSN 2041-1723. doi: 10.1038/ncomms4140. URL http:// www.nature.com/doifinder/10.1038/ncomms4140.

[90] A.M. M El-Sawi, A.S. S Wifi, M.Y. Y Younan, E.A. Elsayed, and B. Basily. Application of folded sheet metal in flat bed solar air collectors. Appl. Therm. Eng., 30(89):864-871, June 2010. ISSN 13594311. doi: 10.1016/ j.applthermaleng.2009.12.018. URL http://www. sciencedirect.com/science/article/B6V1Y-4Y34WHN-2/ 2/54b65d775dd48af9ad32212a4cd49c55http://linkinghu b.elsevier.com/retrieve/pii/S1359431109003652.

[91] C Thill, J Etches, I Bond, K Potter, and P Weaver. Morphing skins. Aeronaut. J., 112(1129):117-139, 2008. URL http://mechanika.fs.cvut.cz/content/files/PhD_grant/ RoyAeroSocMorphSkin.pdf. 
[92] Mark Schenk and SD Guest. Origami folding: A structural engineering approach. In Patsy Wang-Iverson, Robert J. Lang, and Mark YIM, editors, Origami 5 Fifth Int. Meet. Origami Sci. Math. Educ., pages 1-16, 2011. URL http://books.google.com/books?hl=en\&lr=\&id=rk4GSYaV5YC\&oi=fnd\&pg=PA291\&dq=Origami+ Folding:+A+Structural+Engineering+Approach\&ots=ilrn q2y6m6\&sig=nld34zbY3SKDtNwlpjs8VwGEHUs.

[93] Joseph M. Gattas and Zhong You. Geometric assembly of rigid-foldable morphing sandwich structures. Eng. Struct., 94: 149-159, 2015. ISSN 01410296. doi: 10.1016/j.engstruct.2015.03.019. URL http://linking hub.elsevier.com/ retrieve/pii/S0141029615001558.

[94] Matthew Santer and Sergio Pellegrino. Concept and Design of a Multistable Plate Structure, July 2011. ISSN 10500472. URL http://dx.doi.org/10.1115/1.4004459.

[95] Saad Ahmed, Carlye Lau, Adrienne Crivaro, Kevin McGough, Robert Sheridan, Mary Frecker, Paris von Lockette, Zoubeida Ounaies, Timothy Simpson, JyhMing Lien, and Rebecca Strzelec. Multi-Field Responsive Origami Structures: Preliminary Modeling and Experiments. In Vol. 6B 37th Mech. Robot. Conf. ASME, August 2013. ISBN 978-0-7918-5594-2. doi: 10.1115/DETC2013-12405. URL http://proceedings. asmedigitalcollection.asme.org/proceeding. aspx?doi= 10.1115/DETC2013-12405.

[96] Edwin A Peraza-Hernandez, Darren J Hartl, and Richard J Malak Jr. Design and numerical analysis of an SMA mesh-based self-folding sheet. Smart Mater. Struct., 22(9):094008, September 2013. ISSN 0964-1726. doi: 10.1088/0964-1726/22/9/094008. URL http://stacks. iop.org $/ 0964-1726 / 22 / \mathrm{i}=9 / \mathrm{a}=094008$ ? $\mathrm{key}=$ crossref. 4d4a803cbb577d60d09fb1 fec28bd2a4.

[97] Ronald D. Resch. Self-supporting structural unit having a series of repetitious geometrical modules, 1968.

[98] Ronald D. Resch. The topological design of sculptural and architectural systems. In Proc. June 4-8, 1973, Natl. Comput. Conf. Expo. - AFIPS '73, page 643, New York, New York, USA, 1973. ACM Press. doi: 10.1145/ 1499586.1499744. URL ttp://portal.acm.org/citation. cfm?doid=1499586.1499744.

[99] Tomohiro Tachi. Designing Freeform Origami Tessellations by Generalizing Resch's Patterns. J. Mech. Des., 135 (11):111006, October 2013. ISSN 1050-0472. doi: 10.1115/1.4025389. URL http://mechanicaldesign. asmedigitalcollection.asme.org/article.aspx?doi=10.111 5/1.4025389http://origami.c.u-tokyo.ac. jp/\$sim\$tachi/ cg/FreeformOrigamiTessellationsTachi2013ASME.pdf.

[100] Alfred Brunner. Expansible surface structure, January 1968. URL http://www.google.com/patents/US3362118.

[101] Mark Schenk. Folded Shell Structures. PhD thesis, University of Cambridge, 2011.

[102] Kenneth C Cheung, Tomohiro Tachi, Sam Calisch, and Koryo Miura. Origami interleaved tube cellular materials. Smart Mater. Struct., 23(9):094012, 2014. ISSN 09641726. doi: 10.1088/0964-1726/23/9/094012. URL http://stacks.iop. org/0964-1726/23/i=9/a=094012?key= crossref.5a56f20ecc7948e11a834a6628e1f1b0.

[103] Valentina Beatini. Translational method of designing folded plate structures. Int. J. Sp. Struct., in-press, 2015.

[104] Ruikang Xie, Yan Chen, and Joseph M. Gattas. Parametrisation and application of cube and eggboxtype folded geometrics. Int. J. Sp. Struct., in-press, 2015.
[105] Tomohiro Tachi. One-dof cylindrical deployable structures with rigid quadrilateral panels. In Proc. IASS Symp., pages 2295-2305, 2009. ISBN 978-84-8363461-5. URL http://riunet.upv.es/handle/10251/7277.

[106] Wei Yao and Jian S. Dai. Dexterous Manipulation of Origami Cartons With Robotic Fingers Based on the Interactive Configuration Space. J. Mech. Des., 130(2): 022303, 2008. ISSN 10500472. doi: 10.1115/1.2813783. URL http: //mechanicaldesign.asmedigitalcollection.asme. org/article.aspx? articleid=1449633.

[107] Martin Trautz, Hans Willi Heyden, Ralf Herkrath, Thorsten Pofahl, Gerhard Hirt, Babak Taleb-Araghi, and David Bailly. Herstellung frei geformter, selbst tragender Faltstrukturen aus Stahlblech mit der inkrementellen Blechumformung (IBU). Stahlbau, 81(12):959-967, December 2012. ISSN 00389145. doi: 10.1002/stab.201201637. URL http://doi.wiley. com/ 10.1002/stab.201201637.

[108] Ralf Herkrath and Martin Trautz. Starre Faltungen als Leichtbauprinzip im Bauwesen. Bautechnik, 88(2): 80-85, February 2011. ISSN 09328351. doi: 0.1002/bate.201110007. URL ttp://doi.wiley.com/ 10.1002/bate. 201110007 .

[109] Arne Künstler and Martin Trautz. Wandelbare Faltungen aus biegesteifen Faltelementen. Bautechnik, 88(2): 86-93, February 2011. ISSN 09328351. doi: 10.1002/bate.201110008. URL http://doi.wiley.com/ 10.1002/bate. 201110008 .

[110] Jian-Min Li and Jan Knippers. Segmental timber plate shell for the Forstpavillon Schwäbisch Gmünd-The application of finger joint in plate structures. Int. J. Sp. Struct., in-press, 2015.

[111] Koryo Miura. Map Fold a La Miura Style, Its Physical Characteristics and Application to the Space Science. In Res. Pattern Form., pages 77-90. R. Takaki, ktk scient edition, 1994.

[112] Koryo Miura and M Natori. 2-D array experiment on board a space flyer unit. Sp. Sol. Power Rev., 5: 345-356, 1985.

[113] Robert J. Lang. Origami: Complexity in Creases (Again). Eng. Sci., pages 8-19, 2004.

[114] Petra Gruber, Sandra Häuplik, Barbara Imhof, Kürsad Özdemir, Rene Waclavicek, and Maria Antoinetta Perino. Deployable structures for a human lunar base. Acta Astronaut., 61(1-6):484-495, 2007. ISSN 00945765. doi: 10.1016/j.actaastro.2007. 01.055.

[115] R. Chudoba, J. van der Woerd, M. Schmerl, and J. Hegger. ORICRETE: Modeling support for design and manufacturing of folded concrete structures. Adv. Eng. Softw., June 2013. ISSN 09659978. doi: 10.1016/ j.advengsoft.2013.05.004. URL http://linkinghub. elsevier.com/retrieve/pii/S0965997813000665.

[116] F. Lechenault, B. Thiria, and M. Adda-Bedia. Mechanical response of a creased sheet. Phys. Rev. Lett., 112(24):1-5, 2014. ISSN 10797114. doi: 10.1103/ PhysRevLett.112.244301.

[117] Marcel Hassis and Yves Weinand. Origamifaltwerke Neue Anwendung für Brettsperrholzplatten. 39. SAH Fortbildungskurs, pages 175-182, 2007.

[118] Stéphane Roche, Georoy Mattoni, and Yves Weinand. Rotational Stiffness at Ridges of Timber Folded-plate Structures. Int. J. Sp. Struct., in-press, 2015. 
[119] Andrea Stitic, Christopher Robeller, and Yves Weinand. Timber Folded Plate Structures - Folded Form Analysis. Int. J. Sp. Struct., in-press, 2015.

[120] Christopher Robeller. Interlocking folded plate Integrated mechanical attachment for structural wood panels. Int. J. Sp. Struct., in-press, 2015.

[121] Philippe G. Ciarlet and Véronique Lods. Asymptotic analysis of linearly elastic shells. I. Justification of membrane shell equations. Arch. Ration. Mech. Anal., 136(2):119-161, December 1996. ISSN 0003-9527. doi: 10.1007/BF02316975. URL http://www.springerlink. com/index/E2403564W3142N42.pdfhttp://www.spring erlink. com/index/10.1007/BF02316975.

[122] B. Basily and E.A. Elsayed. Dynamic axial crushing of multilayer core structures of folded Chevron patterns. Int. J. Mater. Prod. Technol., 21(1/2/3):169, 2004. ISSN 0268-1900. doi: 10.1504/IJMPT.2004.004750. URL http://www.inderscience.com/link.php?id=4750.

[123] M.Q. Nguyen, S.S. Jacombs, R.S. Thomson, D Hachenberg, and M.L. Scott. Simulation of impact on sandwich structures. Compos. Struct., 67(2):217-227, February 2005. ISSN 02638223. doi: 10. 1016/ j.compstruct.2004.09.018. URL http://www.science direct.com/science/article/B6TWP-4DTBV6Y-3/2/ 27b185d6e21e57d1f8cb7b3ed7fd3ac5http://linkinghub. elsevier.com/retrieve/pii/S0263822304003290.

[124] M. Kintscher, L. Kärger, a. Wetzel, and D. Hartung. Stiffness and failure behaviour of folded sandwich cores under combined transverse shear and compression. Compos. Part A Appl. Sci. Manuf., 38(5):1288-1295, May 2007. ISSN 1359835X. doi: 10. 1016/ j.compositesa.2006.11.008. URL http://www.science direct.com/science/article/B6TWN-4MV71TM1/2/75a32b5f32913f21a03408927e43d577http://linking hub.elsevier.com/retrieve/pii/S1359835X06003368.

[125] Sebastian Fischer, Klaus Drechsler, Sebastian Kilchert, and Alastair Johnson. Mechanical tests for foldcore base material properties. Compos. Part A Appl. Sci. Manuf., 40(12):1941-1952, December 2009. ISSN 1359835X. doi: 10. 1016/j.compositesa.2009.03.005. URL http://www.sciencedirect.com/science/article/B6TWN4VXTSTK-2/2/ a347db537ef46087ea1bd6c6fcecf0fc http://linkinghub.elsevier.com/retrieve/pii/S1359835X0 9000724.

[126] Sebastian Heimbs, J. Cichosz, M. Klaus, Sebastian Kilchert, and Alastair Johnson. Sandwich structures with textile-reinforced composite foldcores under impact loads. Compos. Struct., 92(6):1485-1497, May 2010. ISSN 02638223. doi: 10.1016/ j.compstruct. 2009.11.001. URL http://linkinghub.elsevier.com/ retrieve/pii/S026382230900470Xhttp://www.science direct.com/science/article/B6TWP-4XNF467-1/2/ 9becb70f4e7e28ddf8179475dad75f73.

[127] E. Baranger, C. Cluzel, and P.-A. Guidault. Modelling of the Behaviour of Aramid Folded Cores Up to Global Crushing. Strain, 47:170-178, December 2011. ISSN 00392103. doi: 10.1111/j.1475-1305.2010.00753.x. URL http://doi. wiley.com/10.1111/j.1475-1305. $2010.00753 . x h t t p: / / d x . d o i . o r g / 10.1111 / j .1475-$ 1305.2010.00753.x.

[128] Falk Hähnel, Klaus Wolf, Andreas Haue, Kirill a. Alekseev, and Il'dus M. Zakirov. Wedge-shaped folded sandwich cores for aircraft applications: from design and manufacturing process to experimental structure validation. CEAS Aeronaut. J., 2(1-4):203-212, August 2011. ISSN 1869-5582. doi: 10.1007/s13272-011-0014-8. URL http://www.springerlink. com/index/10.1007/ s13272-011-0014-8.

[129] Marc Grzeschik. Performance of Foldcores Mechanical Properties and Testing. In Vol. 6B 37th Mech. Robot. Conf., page V06BT07A042. ASME, August 2013. ISBN 978-0-7918-5594-2. doi: 10.1115/DETC2013-13324. URL http: //proceedings.asmedigitalcollection.asme. org/proceeding.aspx?doi=10.1115/DETC2013-13324.

[130] Ralf Sturm, Yves Klett, Ch. Kindervater, and H. Voggenreiter. Failure of CFRP airframe sandwich panels under crash-relevant loading conditions. Compos. Struct., 112:11-21, June 2014. ISSN 02638223. doi: 10.1016/j.compstruct.2014.02.001. URL http://linking hub.elsevier.com/retrieve/pii/S0263822314000580.

[131] Ralf Sturm and Sebastian Fischer. Virtual Design Method for Controlled Failure in Foldcore Sandwich Panels. Appl. Compos. Mater., 2015. ISSN 0929-189X. doi: 10.1007/s10443-015-9436-5. URL http://link. springer.com/10. 1007/s10443-015-9436-5.

[132] Sicong Liu, Guoxing Lu, Yan Chen, and Yew Wei Leong. Deformation of the Miura-Ori Patterned Sheet. Int. J. Mech. Sci., 2015. ISSN 00207403. doi: 10.1016/j.ijmecsci.2015.05.009. URL http://linkinghub. elsevier.com/retrieve/ pii/S0020740315001897.

[133] Sebastian Fischer. Aluminium foldcores for sandwich structure application: Mechanical properties and FE-simulation. Thin-Walled Struct., 90:31-41, 2015. ISSN 02638231. doi: 10.1016/j.tws.2015.01.003. URL http://linkinghub. elsevier.com/retrieve/pii/ S0263823115000063.

[134] E. Baranger, P.-A. Guidault, and C. Cluzel. Numerical modeling of the geometrical defects of an origami-like sandwich core. Compos. Struct., 93(10):2504-2510, September 2011. ISSN 02638223. doi: 10. 1016/j.compstruct.2011.04.011. URL http://www. sciencedirect.com/science/article/B6TWP-52MJ8WR3/2/1c040e8a764abfe5ba437c2e003a9cedhttp://linking hub.elsevier.com/retrieve/pii/S0263822311001358.

[135] L. P. Shabalin, A. V. Gorelov, I. N. Sidorov, V. I. Khaliulin, and I. V. Dvoyeglazov. Calculation of the parameters of stress-strain and ultimate states of composite foldcores under transverse compression and shear. Mech. Compos. Mater., 48 (4):415-426, September 2012. ISSN 0191-5665. doi: 10.1007/ s11029-012-9287-1. URL http://link.springer.com/ article/10.1007/s11029-012-9287-1/fulltext.html.

[136] Joseph M. Gattas and Zhong You. Quasi-Static Impact Response of Alternative Origami-Core Sandwich Panels. In Vol. 6B 37th Mech. Robot. Conf., page V06BT07A032. ASME, August 2013. ISBN 978-07918-5594-2. doi: 10.1115/ DETC2013-12681. URL http://proceedings.asmedigitalcollection.asme.org/proce eding.aspx?doi=10. 1115/DETC2013-12681.

[137] Xiang Zhou, Hai Wang, and Zhong You. Mechanical properties of Miura-based folded cores under quasistatic loads. Thin-Walled Struct., 82:296-310, September 2014. ISSN 02638231. doi: 10.1016/ j.tws.2014.05.001. URL http:// linkinghub.elsevier.com/ retrieve/pii/S0263823114001591. 
[138] Sebastian Kilchert, A.F. Johnson, and H. Voggenreiter. Modelling the impact behaviour of sandwich structures with folded composite cores. Compos. Part A Appl. Sci. Manuf., 57:16-26, February 2014. ISSN 1359835X. doi: 10.1016/j.compositesa. 2013.10.023. URL http://linkinghub.elsevier.com/retrieve/pii/ S1359835X13002984.

[139] E. Baranger, P.-A. Guidault, C. Cluzel, and Sebastian Fischer. Generation of physical defects for the prediction of the behaviour of folded cores. In Eur. Conf. Comput. Mech. Palais des Congrès, Paris, Fr. May 1621, 2010, 2010.

[140] Taketoshi Nojima. Development of newly designed ultra-light core structures. JSME Int. J. Ser. A, 49(1): 38-42, 2006. URL http://joi.jlc.jst.go.jp/JST.JSTAGE/ jsmea/49.38?from=Google.

[141] Kazuya Saito and Taketoshi Nojima. Development of Light-Weight Rigid Core Panels. J. Solid Mech. Mater. Eng., 1 (9):1097-1104, 2007. ISSN 1880-9871. doi: 10.1299/jmmp.1.1097. URL http://joi.jlc.jst.go.jp/ JST.JSTAGE/jmmp/1.1097?from=CrossRef.

[142] Kazuya Saito, Sergio Pellegrino, and Taketoshi Nojima. Manufacture of Arbitrary Cross-Section Composite Honeycomb Cores Based on Origami Techniques. J. Mech. Des., 136(5):051011, March 2014. ISSN 10500472. doi: 10.1115/1.4026824. URL http://mechanical design.asmedigitalcollection.asme.org/article.aspx?doi= 10.1115/1.4026824.

[143] Kazuya Saito, Akira Tsukahara, and Yoji Okabe. Designing of Self-Deploying Origami Models Using
Geometrically Misaligned Crease Patterns. In Vol.5B 38th Mech. Robot. Conf., page V05BT08A053, 2014. ISBN 978-0-7918-4637-7. doi: 10.1115/DETC2014-35592. URL http://proceedings.asmedigitalcollection.asme.org/ proceeding. aspx?doi=10.1115/DETC2014-35592.

[144] Ir. Arch. Niels De Temmerman, Marijke Mollaert, Tom Van Mele, and Lars De Laet. Design and Analysis of a Foldable Mobile Shelter System. Int. J. Sp. Struct., 22(3):161-168, September 2007. ISSN 0266-3511. doi: 10.1260/026635107782218868. URL http://multi-science. metapress .com/openurl. asp? genre $=$ article $\& \mathrm{id}=\mathrm{doi}$ : 10.1260/026635107782218868.

[145] Sílvia Edite Marcelo Calretas and Mário Say Ming Kong. Architecture and Paper Structures - Could PaperFolding Become a Methodology in Architecture? Appl. Mech. Mater., 548-549:1627-1634, 2014. ISSN 16627482. doi: 10.4028/www.scientific.net/AMM.548549.1627. URL http://www.scientific.net/AMM.548549.1627.

[146] Heino. Engel. Structure systems. Dt. Verl.-Anstalt, Stuttgart, 1967.

[147] Hani Buri and Yves Weinand. Gefaltet. TEC21, 8:18-22, 2009.

[148] Hani Buri, Ivo Stotz, and Yves Weinand. Curved Folded Plate Timber Structures. In IABSE-IASS Symp., London, 2011.

[149] L. Nagy, L. Rhode-Barbarigos, S. Adriaenssens, and A. Kilian. Conceptual design of a single-crease origami-arc inspired movable footbridge structure. Int. J. Sp. Struct., in-press, 2015. 